\title{
The Munc13 Proteins Differentially Regulate Readily Releasable Pool Dynamics and Calcium-Dependent Recovery at a Central Synapse
}

\author{
Zuxin Chen, ${ }^{1,2 \star}$ Benjamin Cooper, ${ }^{3 \star}$ Stefan Kalla, ${ }^{3}$ Frederique Varoqueaux, ${ }^{3,4,5}$ and Samuel M. Young Jr. ${ }^{2}$ \\ ${ }^{1}$ School of Life Science and Technology, Huazhong University of Science and Technology, Wuhan, Hubei 430074, China, ${ }^{2}$ Research Group Molecular \\ Mechanisms of Synaptic Function, Max Planck Florida Institute, Jupiter, Florida 33458, ${ }^{3}$ Department of Molecular Neurobiology, Max Planck Institute for \\ Experimental Medicine, D-37075 Goettingen, Germany, ${ }^{4}$ German Research Foundation, Research Center for Molecular Physiology of the Brain, D-37075 \\ Goettingen, Germany, and 5Department of Basic Neurosciences, University of Lausanne, CH-1005 Lausanne, Switzerland
}

The Munc13 gene family encodes molecules located at the synaptic active zone that regulate the reliability of synapses to encode information over a wide range of frequencies in response to action potentials. In the CNS, proteins of the Munc13 family are critical in regulating neurotransmitter release and synaptic plasticity. Although Munc13-1 is essential for synaptic transmission, it is paradoxical that Munc13-2 and Munc13-3 are functionally dispensable at some synapses, although their loss in other synapses leads to increases in frequency-dependent facilitation. We addressed this issue at the calyx of Held synapse, a giant glutamatergic synapse that we found to express all these Munc13 isoforms. We studied their roles in the regulation of synaptic transmission and their impact on the reliability of information transfer. Through detailed electrophysiological analyses of Munc13-2, Munc13-3, and Munc13-2-3 knock-out and wild-type mice, we report that the combined loss of Munc13-2 and Munc13-3 led to an increase in the rate of calcium-dependent recovery and a change in kinetics of release of the readily releasable pool. Furthermore, viral-mediated overexpression of a dominant-negative form of Munc13-1 at the calyx demonstrated that these effects are Munc13-1 dependent. Quantitative immunohistochemistry using Munc13fluorescent protein knock-in mice revealed that Munc13-1 is the most highly expressed Munc13 isoform at the calyx and the only one highly colocalized with Bassoon at the active zone. Based on these data, we conclude that Munc13-2 and Munc13-3 isoforms limit the ability of Munc13-1 to regulate calcium-dependent replenishment of readily releasable pool and slow pool to fast pool conversion in central synapses.

\section{Introduction}

The intricate regulation of vesicular neurotransmitter release underlies the ability of a synapse to respond to repeated stimuli and transmit information (Neher and Sakaba, 2008; Klemmer et al., 2009). Among the critical synaptic proteins identified in regulation of synaptic vesicle release are members of the Munc13 protein family (Südhof, 2012), which in mammals consists of four genes: Munc13-1, Munc13-2, Munc13-3, and Munc13-4 (Brose et al., 1995; Koch et al., 2000). Although Munc13-4 is expressed exclusively in peripheral secretory cells (Koch et al., 2000), Munc13-1, b (brain-specific) Munc13-2, ub (ubiquitously dis-

Received Nov. 2, 2012; revised March 29, 2013; accepted April 3, 2013.

Author contributions: Z.C., B.C., F.V., and S.M.Y. designed research; Z.C., B.C., F.V., and S.M.Y. performed research; Z.C., B.C., S.K., and S.M.Y. contributed unpublished reagents/analytic tools; Z.C., B.C., F.V., and S.M.Y. analyzed data; Z.C., B.C., F.V., and S.M.Y. wrote the paper.

This work was supported by the Max Planck Society. We thank Drs. Erwin Neher, Nils Brose, and Lu-Yang Wang for their comments and criticism on this project and manuscript. We thank Cheryl Demczyk for technical assistance for virus construction and assisting in Western blotting. We thank Dr. Monica Montesinos for help with manuscript.

*Z.C. and B.C. contributed equally to this work.

Correspondence should be addressed to Dr. Samuel M. Young, Jr., Research Group Molecular Mechanisms of Synaptic Function, Max Planck Florida Institute, One Max Planck Way, Jupiter, FL 33458. E-mail: sam.young@mpfi.org.

DOI:10.1523/JNEUROSCI.5128-12.2013

Copyright $\odot 2013$ the authors $\quad 0270-6474 / 13 / 338336-16 \$ 15.00 / 0$ tributed), Munc13-2, and Munc13-3 have been reported at central synapses (Augustin et al., 1999b, 2001). Studies with primary hippocampal neurons revealed that the absence of Munc13-1 resulted in a drastic reduction of glutamatergic currents and concluded that Munc13 proteins regulate vesicle priming, the process of making vesicles fusion competent (Augustin et al., 1999a).

Although Munc13 is critical for vesicle priming, previous studies demonstrated that, in the absence of native Munc13-1/2 expression, primary hippocampal neurons exhibit synaptic depression during Munc13-1 overexpression versus synaptic facilitation on ubMunc13-2 overexpression, in response to repetitive stimulation (Rosenmund et al., 2002). This evidence and work from chromaffin cells (Zikich et al., 2008) suggest that different Munc13 isoforms possess different rates of priming and $\mathrm{Ca}^{2+}$. dependent vesicle recruitment and led to the hypothesis that synaptic plasticity is partly determined by Munc13-1 coexpression with alternative Munc13 isoforms. However, emerging evidence from other synapses using either the Munc13-2 or Munc13-3 knock-out (KO) mice has shown that the reality is more complex (Augustin et al., 2001; Bao et al., 2010; Breustedt et al., 2010). In hippocampal mossy fiber synapses, loss of Munc13-2 caused increased frequency-dependent facilitation but did not affect other hippocampal synapses (Breustedt et al., 2010). Loss of Munc13-3 
increased facilitation in cerebellar parallel fiber-Purkinje cell and granule cell-basket cell synapses but had no effect at the granule cell-stellate cell or granule cell-Purkinje cell synapse (Augustin et al., 2001; Bao et al., 2010).

Based on these previous observations, it remains an open question how Munc13 isoforms help shape short-term plasticity characteristics of synapses. To address these questions, we used the calyx of Held synapse, a giant synapse located in the auditory brainstem that requires intricate interplay between depletion and replenishment of synaptic vesicles in the readily releasable pool (RRP) to ensure synaptic reliability at high rates for proper sound localization. Using Munc13-2, Munc13-3, and Munc13-2/3 deletion mutant mice (Varoqueaux et al., 2002), Munc13-fluorescent protein (XFP) knock-in mice (Kalla et al., 2006; Cooper et al., 2012), and viral-mediated overexpression of a dominantnegative Munc13-1 isoform, we studied the distribution and the functional roles of Munc13s at the calyx. Here we show that (1) Munc13-1, ubMunc13-2, and Munc13-3 are expressed at calyceal synapses, (2) Munc13-1 is the most abundant isoform and the only one highly localized to the active zone (AZ), and (3) combined loss of Munc13-2 and Munc13-3 results in a selective reduction in the slow pool but not fast pool component of the RRP that underpins vesicles available for action potential (AP)evoked release and (4) led to an increase in the rate of calciumdependent recovery. We conclude that, in central synapses, the Munc13 isoforms differentially regulate calcium-dependent recovery and slow pool to fast pool conversion.

\section{Materials and Methods}

Mouse generation and handling. All experiments were performed in accordance with the animal welfare guidelines under the laws of Lower Saxony and the Max Planck Florida Institute for Neuroscience Institutional Animal Care and Use Committee. Generation of Munc13-2 KO and Munc13-3 KO and Munc13-2-3 double KO (DKO) mice have been described previously (Augustin et al., 2001; Varoqueaux et al., 2002). Munc13-2/3 heterozygote mice were obtained after interbreeding of single KOs and further crossed to generate Munc13-2/3 DKO and wild-type (WT) control animals. Experiments were performed in postnatal day 9 (P9) to P11 mice (immature calyces) and P18-P21 mice (functionally mature calyces). Because Munc13-2 WT (derived from Munc13-2 heterozygote strains) and Munc13-3 WT (derived from Munc13-3 heterozygote strains) electrophysiological responses were indistinguishable, we used the Munc13-2 WT as control to compare with Munc13-2 KO and Munc13-3 KO (see Table 2, P18-P21 group). In Figure 6A2, the calciumdependent recovery extent of Munc13-2 WT (data not shown) was similar as Munc13-2-3 WT (derived from Munc13-2-3 heterozygote), we used Munc13-2-3 WT as control to compare with other groups. Munc13-XFP mice have been described previously (Kalla et al., 2006; Cooper et al., 2012). Either sex of mice was used in all experiments.

Slice preparation. Acute brainstem slices containing the median nucleus of the trapezoid body (MNTB) were prepared from WT and KO mice using a Leica VT 1200 vibratome (P9-P11: 200- to 220- $\mu$ m-thick slices; P18-P21, 280- to 300- $\mu$ m-thick slices). Slices were immediately transferred to an incubation beaker containing standard extracellular solution $\left(37^{\circ} \mathrm{C}\right.$, continuously bubbled with $\left.95 \% \mathrm{O}_{2}-5 \% \mathrm{CO}_{2}\right)$ with the following (in $\mathrm{mm}$ ): $125 \mathrm{NaCl}, 2.5 \mathrm{KCl}, 1 \mathrm{MgCl}_{2}, 2 \mathrm{CaCl}_{2}, 25$ glucose, 25 $\mathrm{NaHCO}_{3}, 1.25 \mathrm{NaH}_{2} \mathrm{PO}_{4}, 0.4 \mathrm{~L}$-ascorbic acid, 3 myo-inositol, and $2 \mathrm{Na}-$ pyruvate, $\mathrm{pH} 7.3-7.4$ ( $\sim 310 \mathrm{mOsm})$. After an $\sim 45 \mathrm{~min}$ incubation, slices were transferred to a recording chamber with the same saline at room temperature $(\mathrm{RT})\left(\sim 25^{\circ} \mathrm{C}\right)$.

Construction of a Munc13-1(1-451) dominant-negative recombinant adenoviral vector. Munc13-1 cDNA was codon optimized for expression in mammals (Geneart). The fragment encoding for amino acids 1-451 of Munc13-1 was amplified by PCR and cloned in-frame with a C-terminal HA tag into the high expression level cassette pUNISHER (Young and Neher, 2009; Montesinos et al., 2011). Second-generation recombinant adenoviral vectors (rAds), coexpressing the Munc13-1(1-451)-HA under the control of pUNISHER and EGFP under control of the $470 \mathrm{bp}$ human synapsin promoter, were produced as described previously (Young and Neher, 2009; Montesinos et al., 2011). Viral vectors were double cesium purified and titrated using the limiting dilution assay (Montesinos et al., 2011). Expression of Munc13-1(1-451)-HA was confirmed by infecting E2T cells at a dose of 10:1 viral particles/cells and were harvested after $48 \mathrm{~h}$. One-fifth of the cells were mixed with standard protein loading buffer, run by SDS-PAGE, and processed for Western blot analysis using standard techniques. Munc13-1(1-451)-HA expression was detected using antibodies against Munc13-1 (catalog \#126 103; Synaptic Systems) or HA (clone 16B12; Covance) in conjunction with appropriate secondary HRP antibodies (1:2000) using the Supersignal West Pico detection system (Pierce). Signal was captured using a Syngene G-box and analyzed using Syngene Gel Doc Software (Syngene).

Animal surgery. Newborn (P0) Munc13-2-3 DKO mice were anesthetized by hypothermia as described previously (Pilpel et al., 2009). Briefly, mice were cooled for $5 \mathrm{~min}$ in an ice bath, and then a total of 1-2 $\mu \mathrm{l}$ of second-generation rAd Munc13-1(1-451)-HA $\left(1 \times 10^{7}\right.$ transducing units $/ \mu \mathrm{l}$ ) was injected into the cochlear nucleus over 2 min using a glass needle (Blaubland; IntraMARK). Afterward, the glass needle was left in place for $1 \mathrm{~min}$ and then slowly removed. Animals were then placed under a warm lamp of $37^{\circ} \mathrm{C}$ and allowed to recover. After full recovery, they were then returned to their respective cages. Subsequently, animals were killed either $9-11$ or $18-21 \mathrm{~d}$ later for all experiments. This procedure and all surgery experiments were performed under the approved protocols that conform to the guidelines of the Max Planck Florida Institute for Neuroscience Institutional Animal Care and Use Committee.

Electrophysiology. Fiber stimulation was performed as described previously (Forsythe and Barnes-Davies, 1993a,b). Briefly, to record APevoked EPSCs, a presynaptic axon was stimulated by using a bipolar electrode placed halfway between brainstem midline and MNTB. Postsynaptic MNTB neurons were whole-cell voltage clamped at $-60 \mathrm{mV}$ using an EPC10/2 amplifier controlled by the Patchmaster Software (HEKA). To identify calyces transduced with the Munc13-1(1-451)-HA virus, the slice was illuminated at an excitation wavelength of $480 \mathrm{~nm}$ using a Polychrome V xenon bulb monochromator (TILL Photonics). During recording in P9-P11 mice, the standard extracellular solution was supplemented with $2 \mathrm{~mm} \gamma$-D-glutamylglycine ( $\gamma$-DGG) (Tocris Bioscience) to minimize saturation, $20 \mu \mathrm{M}$ D-AP-5 (Tocris Bioscience) to block the NMDA receptors, and $20 \mu \mathrm{M}$ bicuculline (Tocris Bioscience) and $5 \mu \mathrm{M}$ strychnine (Tocris Bioscience) to block IPSCs. In P18-P21 mice, $0.25 \mathrm{~mm}$ kynurenic acid (Tocris Bioscience) was used instead of 2 mM $\gamma$-DGG. Patch pipettes had a resistance $\sim 3.0-4.5 \mathrm{M} \Omega$ and filled with the following (in mM): 130-145 Cs-gluconate, 20 tetraethylammonium (TEA)-Cl, 10 HEPES, $5 \mathrm{Na}_{2}$-phosphocreatine, $4 \mathrm{MgATP}, 0.3 \mathrm{NaGTP}, 6$ QX-314, and 5 EGTA, pH 7.25 (320 mOsm). Postsynaptic series resistance (3-8 M $\Omega$ ) was compensated online so that the residual resistance became 2.5-3.0 M $\Omega$, and the remaining resistance was further compensated offline. For pair recording, the presynaptic calyx of Held terminal and MNTB were simultaneously whole-cell voltage clamped at -80 and $-60 \mathrm{mV}$, respectively, by using a HEKA EPSC 10/2 amplifier controlled by the Patchmaster software (HEKA). The presynaptic patch pipettes (4-6 M $\Omega$ ) contained the following (in $\mathrm{mM}$ ): 130-145 Cs-gluconate, 20 TEA-Cl, 10 HEPES, $5 \mathrm{Na}_{2}$-phosphocreatine, $4 \mathrm{MgATP}, 0.3 \mathrm{NaGTP}$, and 0.5 EGTA, pH 7.25 (325-340 mOsm). The postsynaptic pipette contained the same solution as the presynaptic one, except that EGTA was increased to $5 \mathrm{~mm}$. The presynaptic series resistance $(<20 \mathrm{M} \Omega)$ was compensated to $8 \mathrm{M} \Omega$ by the amplifier online. During the pair recording, the extracellular solution were supplemented with $1 \mu \mathrm{M}$ tetrodotoxin (Alomone Labs), $10 \mathrm{~mm}$ TEA (Sigma) to block voltage-activated sodium and potassium current, $50 \mu \mathrm{M}$ D-AP-5 (Tocris Bioscience), $100 \mu \mathrm{M} \mathrm{cy-}$ clothiazide (Tocris Bioscience), and $2 \mathrm{~mm} \gamma$-DGG as described previously (Young and Neher, 2009).

Data analyses. Electrophysiological data were analyzed offline with custom programming written in Igor Pro (version 6.12A; Wavemetrics). Residual series resistance $\left(R_{\mathrm{s}}\right)$ were compensated offline to $0 \mathrm{M} \Omega$ for all EPSCs. Statistics were performed with Prism5 (GraphPad Software). To compare two groups, an unpaired Student's $t$ test was used. To compare 
more than two groups, a one-way ANOVA with a post hoc Tukey's test was used when the data passed Bartlett's test of equal variance; otherwise, a Kruskal-Wallis test with a post hoc Dunn's test was used.

Deconvolution analyses. A deconvolution method was used to estimate the release rate and measure the RRP as described previously (Sakaba and Neher, 2001a). EPSCs evoked by long depolarization $(-80$ to $+70 \mathrm{mV}$ for $2 \mathrm{~ms}$, followed by $50 \mathrm{~ms}$ at $0 \mathrm{mV}$ and then back to $-80 \mathrm{mV}$ ) were deconvolved with miniature EPSC waveform, also taking into account the residual current attributable to delayed clearance of glutamate in the synaptic cleft. Vesicle release rates determined by deconvolution were integrated to obtain cumulative releases, which were further corrected for the refilling of the pool of synaptic vesicles (Sakaba and Neher, 2001a,b). The corrected cumulative releases were fitted with a double exponential to estimate the amount and the time course of the fast and slow components of release.

Western blot analyses of Munc13-1 expression levels. Munc13-1 expression levels were analyzed by Western blot in P19 Munc13-2-3 DKO and WT mice. Calyx/MNTB regions were dissected out from fresh brainstem slices and combined ( $n=3$ mice per genotype). Samples were then homogenized with 10 strokes with a Teflon Potter tissue homogenizer and spun for $30 \mathrm{~min}$ at $4^{\circ} \mathrm{C}$ at a relative centrifugal force of 21,000 in an Eppendorf 5424 tabletop centrifuge. Protein levels were quantified by BCA assay (Pierce). Twenty micrograms of total protein were loaded into individual wells on a SDS-PAGE gel and transferred to nitrocellulose membrane using standard techniques. Munc13-1 and $\beta$-actin were detected using specific antibodies (Munc13-1, 1:1000, catalog \#126-103, Synaptic Systems; $\beta$-actin, 1:5000, catalog \#A-2228, Sigma) and secondary amplification using Pierce West Pico detection system with appropriate secondary HRP antibodies (1:2000). Signal was captured using a Syngene G-box within the linear range of detection capabilities of the 16 bit camera (65,536 bits of data) and analyzed using Syngene Gel Doc Software. Munc13-1 signals were then normalized to the respective $\beta$-actin signals. Subsequently, the normalized Munc13-1 DKO signal was divided by the normalized Munc13-1 WT signal. A $t$ test was run to determine any statistically significant differences.

Immunocytochemical detection of Munc13 isoforms. Animals received a lethal dose of Avertin and were transcardially perfused first with saline [ $0.9 \% \mathrm{NaCl}$ in $0.1 \mathrm{M}$ phosphate buffer (PB) for $2 \mathrm{~min}$ ] and then with $4 \%$ paraformaldehyde (PFA) in $0.1 \mathrm{M} \mathrm{PB}, \mathrm{pH} 7.4$ (perfusate volume, $20 \mathrm{ml}$ ). Brains were removed and washed overnight in $0.1 \mathrm{M} \mathrm{PB}, \mathrm{pH} 7.4$, and then $50-\mu \mathrm{m}$-thick vibratome sections were collected through the MNTB. Sections were incubated overnight at $4^{\circ} \mathrm{C}$, in primary antibody mix in $\mathrm{PB}$ containing $3 \%$ normal goat serum and $0.1 \%$ Triton X-100. Munc13 isoform-specific antisera (Cooper et al., 2012) were used at the following dilutions: polyclonal rabbit anti-Munc13-1 (batch " 40 " or "41"; 1:5000), anti-ubMunc13-2 (batch "52"; 1:5000), anti-bMunc13-2 (batch "50"; 1:5000), and anti-Munc13-3 (batch "48"; 1:5000). Incubation in secondary antibodies coupled to Alexa Fluor-488 or Alexa Fluor-555 (1:2000; Invitrogen) was then performed for $1 \mathrm{~h}$ at RT. Images from labeled sections were acquired with an Olympus BX61 microscope and AnalySIS imaging program (Olympus). Image contrast and brightness were adjusted with Photoshop, and figures were compiled with Illustrator (CS2; Adobe Systems).

Quantitative immunocytochemistry. Mice were killed at either P9-P11 or P18-P21 by decapitation after isoflurane anesthesia. Brains were removed and rapidly frozen in isopentane cooled to $-35^{\circ} \mathrm{C}$. Twentymicrometer-thick sagittal sections were made at the cryostat through the MNTB and thaw mounted on Superfrost slides. To ensure comparable fixation and labeling conditions between genotypes, sections from Munc13-1-EYFP, Munc13-2-EYFP, and Munc13-3-EGFP mice were collected on each slide, air dried for $15 \mathrm{~min}$, and immersion fixed in ice-cold 4\% PFA solution (4\% PFA in $0.1 \mathrm{M} \mathrm{PB}, \mathrm{pH}$ 7.4) for $5 \mathrm{~min}$ at RT. Sections were incubated $90 \mathrm{~min}$ at RT in blocking solution $(0.1 \mathrm{M} \mathrm{PB}, 5 \%$ normal goat serum, $0.1 \%$ cold-water fish-skin gelatin, and $0.5 \%$ Triton $\mathrm{X}-100, \mathrm{pH} 7.4)$ and then overnight at $4^{\circ} \mathrm{C}$ with primary antibodies [monoclonal antibody rabbit anti-GFP, G10362, 1:20, Invitrogen; monoclonal antibody mouse anti-Bassoon, SAP7F407, 1:400, Enzo Life Sciences; polyclonal antibody guinea pig anti-vesicular glutamate transporter 1 (VGluT1), catalog \#135 304, 1:1500, Synaptic Systems; and poly- clonal antibody chicken anti-MAP2, catalog \#NB300-213, 1:600, Novus] diluted in incubation buffer $(0.1 \mathrm{M} \mathrm{PB}, 3 \%$ normal goat serum, $0.1 \%$ cold-water fish-skin gelatin, and $0.3 \%$ Triton X-100, pH 7.4). Slides were washed extensively in $\mathrm{PB}$ and then incubated $2 \mathrm{~h}$ at $\mathrm{RT}$ in the dark with fluorescent secondary antibodies (Alexa Fluor 488-coupled goat antirabbit, Alexa Fluor 555-coupled goat anti-mouse, and Alexa Fluor-633 goat anti-chicken at 1:2000; Invitrogen) diluted in incubation buffer. Coverslips were mounted on slides with Aqua-PolyMount (Polysciences). In sagittal sections of the entire brain, the labeling pattern of Munc13-XFPs observed during detection with the anti-GFP antibody correlated well with the known distribution pattern of each WT isoform. No specific anti-GFP immunofluorescence was detected in WT brains.

Confocal laser-scanning micrographs of MNTB neurons and calyces of Held were acquired with a Leica TCS-SP5 confocal microscope equipped with a tunable white light laser and hybrid gallium-arsenidephosphide detectors. An HCX PL APO lambda blue 63×, numerical aperture 1.2 water-immersion objective corrected for coverslip thickness was used to obtain single-plane micrographs at the neuron midline, estimated from the maximal diameter of the MAP-2-labeled soma. Micrographs were imaged in sequential scanning mode with a pinhole diameter of $1 \mathrm{AU}$ and a $10 \times$ electronic zoom, giving pixel dimensions of $x, y=48.1$ $\mathrm{nm}$. Laser power and gain were optimized to ensure that all signals collected were in the linear range of detection. Autofluorescent plastic slides (Chroma Technology) provided an invariable source of fluorescence by which the consistency of excitation light and the detection sensitivity of the microscope could be monitored to ensure comparable imaging conditions between sessions. The particle analysis feature of NIH Image J was used to delineate the boundaries of Bassoon-immunoreactive AZs surrounding the MNTB neurons and to measure the mean signal intensity of Bassoon and GFP signals at the AZ. The minimal background produced by the anti-GFP antibody at AZs was estimated on WT sections and was subtracted in experimental datasets from Munc13-XFP animals before quantitative analysis. Identical parameters were applied to analyze all genotypes.

The ratio of Munc13-XFP/Bassoon signal intensity was calculated for each delineated $\mathrm{AZ}$, and these values were averaged for individual calyces/MNTB neurons. Ratiometrically derived Munc13-XFP signal intensities were normalized to that of Munc13-1-EYFP, because it appeared to be most strongly expressed. The colocalization plugin of NIH Image J was used to graphically represent sites of colocalization between Munc13XFPs and either Bassoon (see Fig. 2) or VGluT1 (see Fig. 3). The plugin overlays 8-bit images from green (Munc13-XFPs) and red (Bassoon or VGluT1) channels and indicates colocalized points in white (display value, 255). Two points were considered colocalized if their respective channel intensities exceeded an arbitrary threshold (set to 40 for both channels), and the ratio of pixel intensities for both channels exceeded $50 \%$. To quantify the degree to which a given Munc13-XFP isoform overlaps with Bassoon at the AZ, the number and mean area of identified sites of colocalization was measured in calyceal profiles from respective genotypes using the analyze particles feature of NIH Image J.

The relative proportion of Bassoon-positive AZs exhibiting colocalization with a given Munc13-XFP isoform was determined by dividing the number of individual colocalized sites by the total number of Bassoon puncta in calceal profiles. This approach is potentially vulnerable to two sources of inaccuracy: (1) low-intensity Munc13-XFP puncta, despite exhibiting AZs localization, may be neglected attributable to the stringency of the colocalization analysis thresholds, and (2) the NIH Image J analyze particles feature occasionally failed to recognize adjacent AZ puncta or sites of colocalization as independent signals. However, all genotypes were subject to the same experimental bias and analyzed under identical conditions.

Statistical analyses were performed with GraphPad Prism (version 6.00; GraphPad Software). Normalized Munc13-XFP signal intensities were compared by unpaired Student's $t$ tests for normally distributed data and by Kolmogorov-Smirnov tests for data exhibiting nonGaussian distributions. Sampled calyces from three animals per genotype were included in the analysis. 

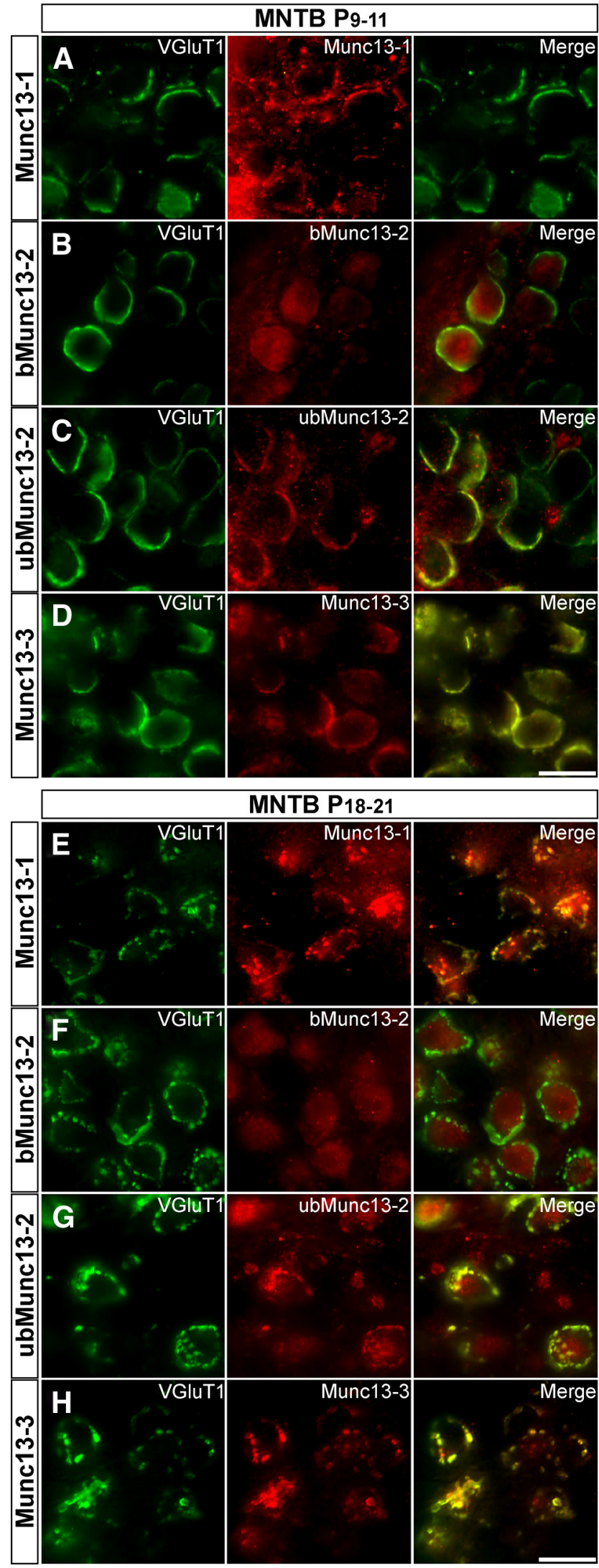

Figure 1. Immunodetection of Munc13s at the calyx of Held using isoform-specific antisera. Wide-field fluorescent micrographs from young (P9-P11, A-D) and mature (P18-P21, $\boldsymbol{E}-\boldsymbol{H})$ calyx of Held synapses in coronal sections through the MNTB of WT mice. Large VGluT1immunoreactive (green, left column) calyces were visualized encompassing the somata of principal MNTB neurons. Immunolabeling with Munc13 isoform-specific antisera (red, middle

\section{Results}

Munc13-1, ubMunc13-2, and Munc13-3 are expressed in the immature and functionally mature calyx of Held/MNTB synapse

To understand how the different Munc13 isoforms regulate short-term plasticity, we first determined which Munc13 isoforms are expressed at the mouse calyx of Held. To do so, we used previously validated isoform-specific antibodies raised against divergent N-terminal sequences of the Munc13 family (Varoqueaux et al., 2005; Cooper et al., 2012) and an antibody detecting the presynaptic marker VGlut1 to label the calyx of Held terminals in auditory brainstem slices from C57BL/6n mice (Fig. 1). Because the presynaptic functional properties and morphology of the calyx change during development (Kandler and Friauf, 1993; Taschenberger and von Gersdorff, 2000; Taschenberger et al., 2002; Fedchyshyn and Wang, 2005), we characterized Munc13 expression profiles from two age groups of mice: (1) P9-P11 (before the onset of hearing, immature calyces); and (2) P18-P21 (after the onset of hearing, functionally mature calyces). Using wide-field fluorescent imaging, Munc13-1, ubMunc13-2, and Munc13-3 could be detected in both immature and functionally mature calyces (Fig. $1 A-H$ ). In contrast, bMunc13-2 did not appear to be expressed at calyx terminals, and the faint cell body labeling observed has been reported previously as nonspecific (Fig. 1 B, F; Cooper et al., 2012). This is the first evidence of a central synapse expressing all three Munc13 isoforms.

\section{Dominant expression of Munc13-1 over Munc13-2 and} Munc13-3 and distinct subsynaptic distributions of three isoforms

Because the Munc13 antibodies used for isoform-specific detection in the calyx were polyclonal antibodies raised against large portions of the respective isoforms, their actual recognition site(s) and affinities are not known and therefore cannot be used to compare the levels of each isoform with respect to one another. Thus, to determine the relative expression levels of the Munc13 isoforms at the calyx of Held, we used Munc13-XFP knock-in mice, in which a native Munc13 is epitope tagged at its $C$ terminus with EYFP or EGFP with no change of function (Kalla et al., 2006; Cooper et al., 2012). First, triple labeling was performed for GFP, the somatic protein MAP-2, and the presynaptic protein VGlut1 in auditory brainstem slices of each strain (Fig. 2). MAP-2 staining allowed one to distinguish calyceal from somatic labeling in Munc13-2-EYFP and Munc13-3-EGFP MNTB neurons (Figs. 2, 3). Using confocal imaging, Munc13 signals mostly appeared as defined puncta (Figs. $2 B-D, 3 A--C$ ), in agreement with previous reports on Munc13 localization (Kalla et al., 2006; Cooper et al., 2012). Munc13-1-EYFP, Munc13-2-EYFP, and Munc13-3EGFP signals were clearly associated with VGluT1-labeled presynaptic specializations, essentially corresponding to calyx of Held terminals (Fig. 2). This correlates well with the calyceal expression of all three Munc13 isoforms assessed above (Fig. 1).

The relative Munc13 levels at AZs of immature and mature calyx synapses were then assessed by a triple labeling for GFP, MAP-2, and the AZ protein Bassoon (Fig. 3). Bassoon immunoreactivity was strictly limited to small fluorescent puncta, consid-

column) revealed that Munc13-1 $(\boldsymbol{A}, \boldsymbol{E})$, ubMunc13-2 $(\boldsymbol{B}, \boldsymbol{F})$, and Munc13-3 $(\boldsymbol{D}, \boldsymbol{H})$ signals overlapped (yellow, right column) with VGluT1 in both young and mature calyces. In contrast, bMunc13-2 staining $(\boldsymbol{B}, \boldsymbol{F})$ only yielded a nonspecific somatic signal. Scale bars, $20 \mu \mathrm{m}$. 


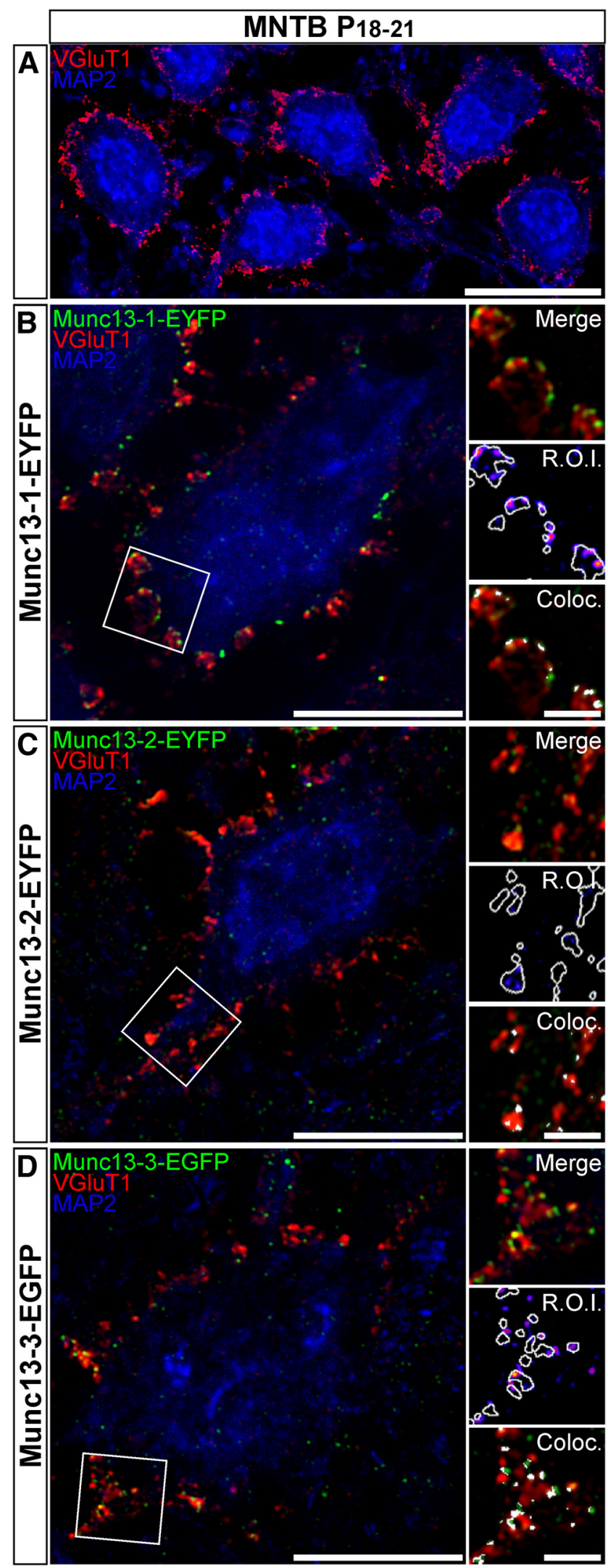

Figure 2. Immunolocalization of Munc 13 isoforms at glutamatergic presynaptic terminals innervating MNTB neurons using Munc13-XFP mice. Single-plane confocal micrographs from mature (P18-P21) calyx of Held synapses in Munc13-1-EYFP (B), Munc13-2-EYFP (C), and Munc13-3-EGFP ( $\boldsymbol{D})$ mice. Glutamatergic terminals (red) innervating MNTB cell bodies (blue) were identified during labeling for VGluT1 and MAP-2. Munc13-XFP signals (green) were detected using an anti-GFP antibody (B-D). In $\boldsymbol{B}-\boldsymbol{D}$, selected regions framed in white are shown ered as AZs, and was used to quantify the total number of AZs sampled in young and mature calyces and the mean number of AZs analyzed per calyx (Table 1). The mean Bassoon signal intensity was similar between age-matched genotypes. When using the same imaging settings for Munc13-1, Munc13-2, and Munc13-3 detection, Munc13-1-EYFP signal was by far the strongest, whereas Munc13-2-EYFP and Munc13-3-EGFP signals were very weak (Fig. $3 D, E$ ). Moreover, we found that Munc13-1 puncta most closely correlated with AZs ( $\sim 70 \%$ of AZs in young and functionally mature calyces; Table 1), whereas Munc13-2 and Munc13-3 were detected as discrete puncta often adjacent to AZs (Munc13-2 puncta overlap with 8 and $10 \%$ of AZs in immature and functionally mature calyces,, respectively; Munc13-3 puncta overlap with 3 and $/ 14 \%$ of AZs in immature and functionally mature calyces, respectively (Fig. 3; Table 1). Interestingly, although Munc13-1 levels (mean signal intensity) remained comparable at the $\mathrm{AZ}$ of immature versus mature calyces, both Munc13-2 and Munc13-3 levels increased significantly during calyx of Held development (Fig. 3D; Table 1). Of note, Munc13-3 was occasionally detected as large, intense punctate signals at a few AZs of the mature calyx. Nevertheless, the mean colocalization area, which measures the degree of overlap between the Munc13 and Bassoon signals, revealed that the degree of overlap of Munc13-1 and Bassoon signals was twofold greater than that of Munc13-2 or Munc13-3 and Bassoon (Fig. $3 F)$, in the immature as well as in functionally mature calyces. Together, our morphological data indicate that Munc13 isoforms are differentially localized in the calyx terminal and confirm that Munc13-1 is the most frequently and most abundantly expressed Munc13 isoform at calyceal AZs.

Single loss or combined loss of Munc13-2 and Munc13-3 does not affect basal synaptic transmission

Previous studies have shown loss of either Munc13-2 or Munc13-3 at synapses had variable effects on synaptic transmission and plasticity characteristics (Augustin et al., 2001; Bao et al., 2010; Breustedt et al., 2010), although the cause of the variable phenotypes is unknown. To characterize potential effects of the individual loss of Munc13-2 or Munc13-3 on synaptic transmission and short-term plasticity, we performed electrophysiological analyses using afferent midline stimulation of the calyx axons, and the resultant AMPA receptor-mediated EPSCs were recorded from voltage-clamped principal cells of the MNTB neurons in Munc13-2 KO or Munc13-3 KO mice at P9-P11 and P18-P21. In both age groups, loss of either Munc13-2 or Munc13-3 had no effect on basal synaptic transmission characteristics (Table 2).

Because there was no significant change in basal synaptic transmission at the calyx of Held in Munc13-2 or Munc13-3 KO animals and there are three Munc13 isoforms coexpressed in this synapse, deletion of one of the isoforms could be easily compensated by the other two isoforms. Thus, it became important to test how the Munc13-2, Munc13-3 DKO affects synaptic transmission. Using identical electrophysiological analysis previously described with the single Munc13-2 KO and Munc13-3 KO

enlarged on the right to illustrate. Merge, The overlay of Munc13-XFP and VGluT1 signals; R.0.I., the outline of VGluT1-immunoreactive presynaptic terminals overlaid with Munc13-XFP signals displayed with the "Fire" lookup table to facilitate visualization; Coloc., the colocalization (in white) between Munc13-XFPs and VGluT1. R.0.I., Region of interest. Scale bars: $\boldsymbol{A}, 20$ $\mu \mathrm{m} ; \boldsymbol{B}-\boldsymbol{D}, 10 \mu \mathrm{m}$; enlargements, $2 \mu \mathrm{m}$. 

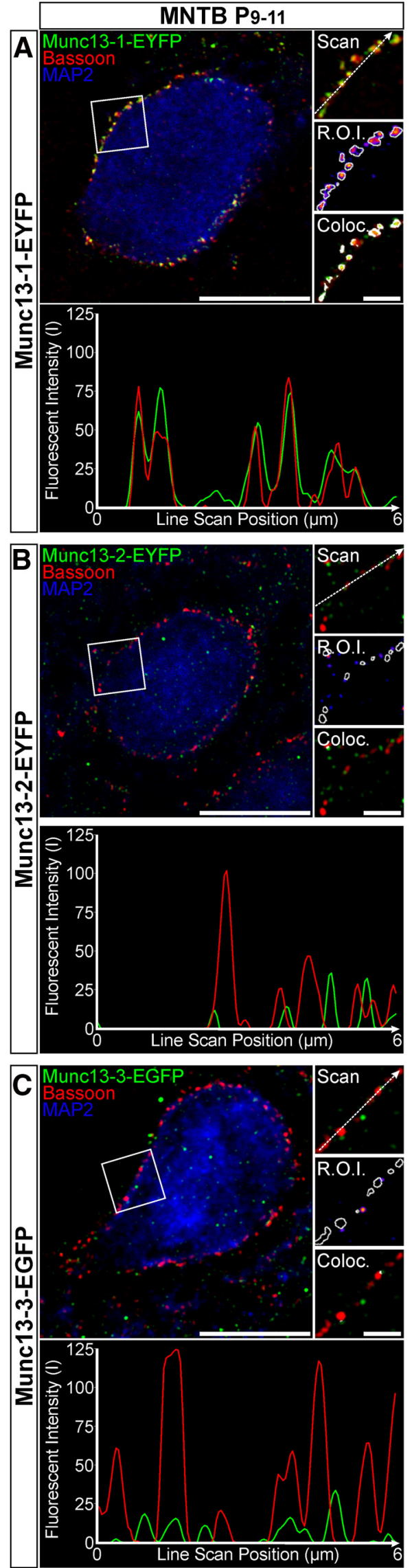
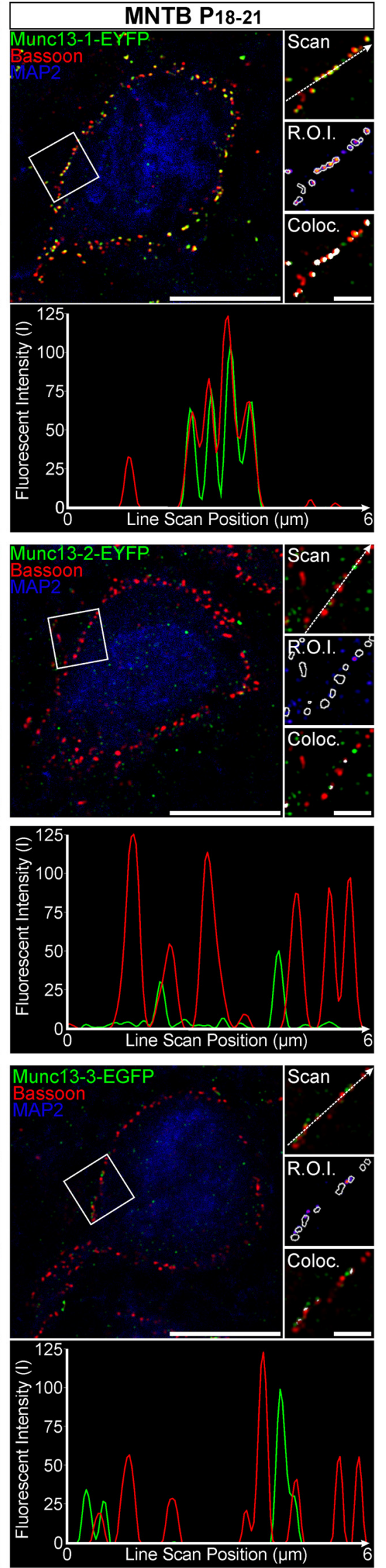
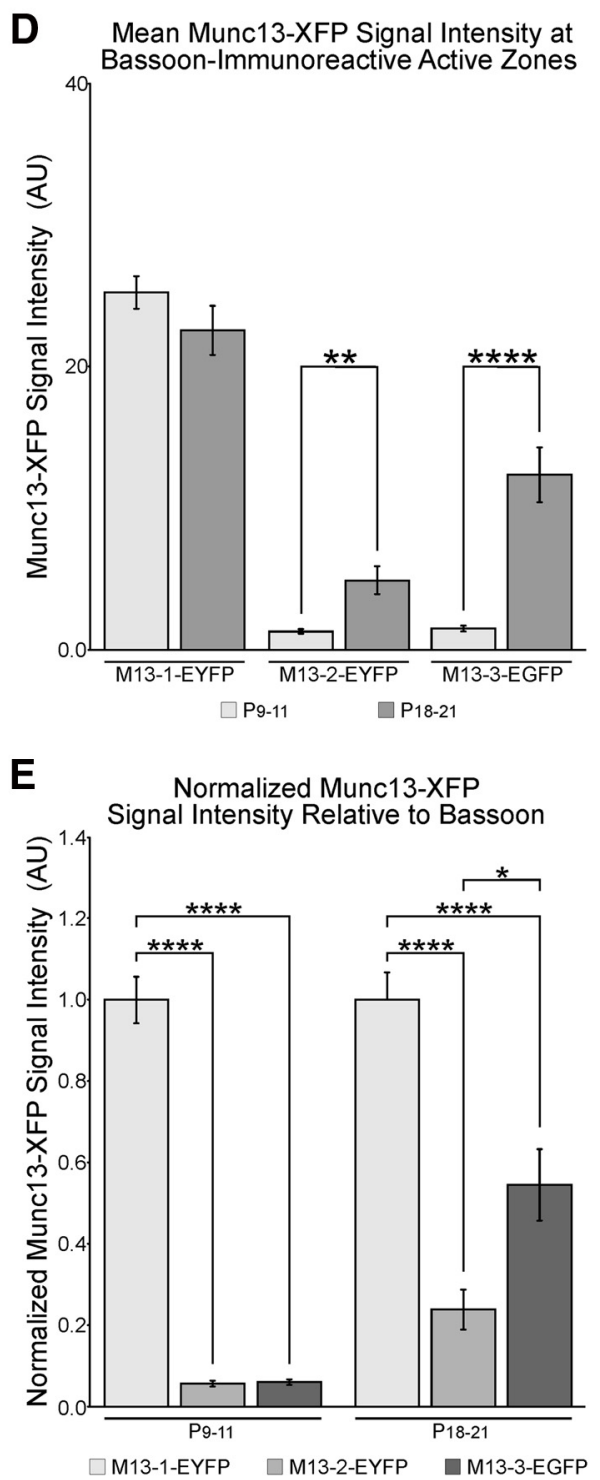

F Normalized Mean Colocalization Area

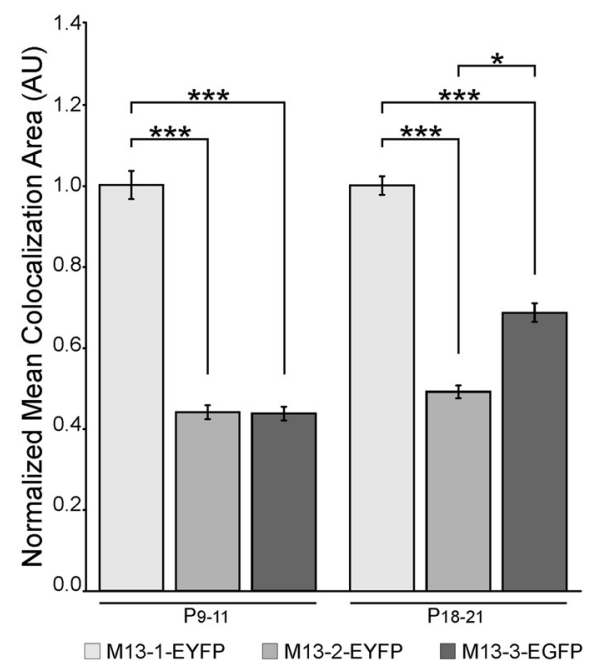

Figure 3. Immunocytochemical analysis and quantitation of Munc13 isoform expression levels at AZs in the MNTB using Munc13-XFP mice. Single-plane confocal micrographs from young (P9-P11, left column) and mature (P18-P21, right column) calyx of Held synapses in Munc13-1-EYFP (A), Munc13-2-EYFP (B), and Munc13-3-EGFP( ) mice. Munc13-XFP (Figurelegend continues.) 
Table 1. Summary of Munc13-XFP signal intensity at Bassoon-immunoreactive active zones

\begin{tabular}{|c|c|c|c|c|c|c|}
\hline & \multicolumn{3}{|l|}{$\mathrm{P9} 9-\mathrm{P} 11$} & \multicolumn{3}{|l|}{$\mathrm{P} 18-\mathrm{P} 21$} \\
\hline & M13-1-EYFP & M13-2-EYFP & M13-3-EGFP & M13-1-EYFP & M13-2-EYFP & M13-3-EGFP \\
\hline Mean Munc13-XFP signal intensity (AU) \pm SEM & $25.28 \pm 1.15$ & $1.30 \pm 0.16$ & $1.52 \pm 0.20$ & $22.59 \pm 1.72$ & $4.91 \pm 0.98$ & $12.38 \pm 1.91$ \\
\hline Normalized signal intensity \pm SEM $^{a}$ & $1.00 \pm 0.06$ & $0.06 \pm 0.01$ & $0.06 \pm 0.01$ & $1.00 \pm 0.07$ & $0.24 \pm 0.05$ & $0.55 \pm 0.09$ \\
\hline $\begin{array}{l}\text { Normalized proportion of AZs exhibiting colocalization with } \\
\text { Munc13-XFP } \pm \text { SEM }\end{array}$ & $1.000 \pm 0.033$ & $0.122 \pm 0.012$ & $0.146 \pm 0.018$ & $1.000 \pm 0.038$ & $0.050 \pm 0.005$ & $0.223 \pm 0.021$ \\
\hline Total number of AZs & 2841 & 2925 & 2988 & 3998 & 4188 & 3923 \\
\hline Number of calyces samples & 42 & 43 & 42 & 52 & 53 & 53 \\
\hline Number of animals & 3 & 3 & 3 & 3 & 3 & 3 \\
\hline
\end{tabular}

${ }^{a}$ Normalized Munc13-XFP signal intensity to Munc13-1-EYFP signal intensity.

${ }^{b}$ Normalized mean colocalization area of Munc13-XFP and Bassoon to the mean colocalization area of Munc13-1-EYFP and Bassoon at the Bassoon-immunoreactive AZs.

animals, we found that no significant difference was detected in resultant AP-evoked EPSC in either P9-P11 or P18-P21 mice in the Munc13-2-3 DKO calyces (Fig. 4B1,B2; Table 2). Based on these data, we conclude that loss of Munc13-2 and Munc13-3 has no effect on basal synaptic transmission at the calyx of Held.

\section{Afferent fiber stimulation at $100 \mathrm{~Hz}$ demonstrates combined loss of Munc13-2 and Munc13-3 does not have an effect on the short-term plasticity kinetics and size of the RRP available for AP-evoked release}

It has been demonstrated that Munc13 isoforms can differentially affect short-term plasticity (Rosenmund et al., 2002). Specifically, ubMunc13-2 has been demonstrated to differentially affect vesicle priming and lead to frequency-dependent synaptic facilitation, in contrast to observations made in Munc13-1-expressing synapses (Rosenmund et al., 2002). The effects of Munc13-3 on vesicle priming are unknown. Because it is well established that the regulation of vesicular priming impacts the RRP size and short-term plasticity characteristics of a synapse (Neher and Sakaba, 2008; Pan and Zucker, 2009), we measured the RRP and the kinetics of frequency-dependent plasticity using $100 \mathrm{~Hz}$ stimulation frequency (in immature and functionally mature calyces) on the Munc13-2 or Munc13-3 KO background to determine whether their loss affected size and the kinetics of the RRP available for AP-evoked release (Schneggenburger et al., 1999; Neher and Sakaba, 2008). Based on our results, we found no significant difference in RRP size in immature or functionally mature calyces (Table 2). To analyze the kinetics of depression, we normalized the EPSC amplitudes of the train to the first EPSC amplitude and then averaged into each genotype and fit it with a

\section{$\leftarrow$}

(Figure legend continued.) signals (green) were detected using an anti-GFP antibody, AZs (red) were defined during labeling for the AZ protein Bassoon, and somata of principal MNTB neurons (blue) were labeled with MAP-2. Regions framed in white are enlarged and represented on the right in three formats: Scan, merged Munc13-XFP and Bassoon signals on which a dotted, white line illustrates the position of a $6-\mu \mathrm{m}$-long line scan along which the respective fluorescent intensities are plotted (bottom panels in $\boldsymbol{A}-\boldsymbol{C}$; R.0.I., white outlines delineating Bassoon-immunoreactive AZs served as the region of interest in which the signal intensity of Munx13-XFPs (displayed with "Fire " lookup table to facilitate visualization of signal intensities) were quantified (Fig. 2D); Coloc., colocalization (in white) between Munc13-XFPs and Bassoon. R.0.I., Region of interest. Scale bars: $10 \mu \mathrm{m}$; enlargement, $2 \mu \mathrm{m}$. D, Mean Munc13XFP signal intensity at Bassoon-immunoreactive AZs in young (P9-P11) and mature (P18P21) calyx of Held synapses. $\boldsymbol{E}$, Normalized Munc13-XFP signal intensity relative to Bassoon in young and mature calyces. $\boldsymbol{F}$, Mean colocalization area of Munc13-XFP and Bassoon normalized to the mean colocalization area of Munc13-1-EYFP and Bassoon. ${ }^{*} p<0.05$; ${ }^{* *} p<0.01$; ${ }^{* * *} p<0.001 ; * * * p<0.0001$. single-exponential curve (Wang and Kaczmarek, 1998; Neher and Sakaba, 2008). In both immature and mature calyces, there is no difference in the kinetics of depression or steady-state levels between the Munc13-2 KO and Munc13-3 KO and control group (data not shown).

Because our data demonstrated that, unlike climbing fiberPurkinje cell synapses in the cerebellum, mossy fiber synapses in the hippocampus, or granule cell-basket cell synapses in the cerebellum, synaptic plasticity remain unaltered by the single deletion of Munc13-2 or Munc13-3 in the calyx of Held synapse, we performed similar analysis with Munc13-2-3 DKO background as described previously to measure RRP and kinetics. Similar to the single $\mathrm{KO}$ of Munc13-2 and Munc13-3, combined loss of Munc13-2 and Munc13-3 lead to no change in the RRP size and short-term plasticity characteristics as measured at $100 \mathrm{~Hz}$ stimulation (Fig. 5; Table 2). Together, our data show that short-term plasticity as measured at $100 \mathrm{~Hz}$ and subsequently the RRP available for AP-evoked release at the calyx of Held are unaffected by the loss of both Munc13-2 and Munc13-3.

\section{Perturbation of Munc13-1 by overexpression of a Munc13-1 dominant negative impacts synaptic transmission and plasticity at the calyx of Held}

Because our immunohistochemistry data identified Munc13-1 as the dominant isoform and the combined loss of Munc13-2 and Munc13-3 had minimal effect on basal synaptic transmission at the calyx, we sought to perturb Munc13-1 function to prove that loss of Munc13-1 function affects synaptic transmission at the calyx. Because Munc13-1 KO animals die perinatally (Augustin et al., 1999b) and conditional Munc13-1 KO animals are not available at this time point, we used a viral high-level dominantnegative strategy using rAds (Young and Neher, 2009; Montesinos et al., 2011) to overexpress the previously published Munc13-1 dominant-negative Munc13-1(1-451) (Betz et al., 2001) to perturb Munc13-1 function at the calyx of Held. To do so, $\mathrm{P} 0$ Munc13-2-3 DKO mice were injected with the viral vector, and then afferent fiber stimulation recordings were performed stimulating only those calyces that had been transduced by the viral vector. Figure 4 demonstrates that expression of the Munc13-1 N-terminal dominant negative leads to a significant reduction in the EPSC at both age groups [P9-P11 synapse, DKO vs Munc13-1(1-451), $2.00 \pm 0.20$ vs $0.59 \pm 0.06 \mathrm{nA}, n=18$ vs $n=18$; P19-P21 synapse, DKO vs Munc13-1(1-451), $5.29 \pm$ 0.51 vs $2.57 \pm 0.32 \mathrm{nA}, n=24$ vs $n=15$ ] (Table 2 ). In addition, overexpression of the dominant negative lead to significant decreases in the measurable RRP size using $100 \mathrm{~Hz}$ stimulation in 
Table 2. Summary of synaptic response from WT, Munc13-2 K0, Munc13-3 KO, Munc13-2-3 DKO, and overexpression of Munc13-1(1-451) calyx of Held synapse

\begin{tabular}{|c|c|c|c|}
\hline Genotype & Values \pm SEM $(n)$ & Statistical test & $p$ value \\
\hline \multicolumn{4}{|l|}{ P9-P11 synapse } \\
\hline \multicolumn{4}{|l|}{ eEPSC amplitude (nA) } \\
\hline WT & $1.47 \pm 0.13(28)$ & Student's $t$ test & $p>0.05$ \\
\hline Munc13-2 K0 & $1.25 \pm 0.08(23)$ & & \\
\hline WT & $1.57 \pm 0.16(17)$ & Student's $t$ test & $p>0.05$ \\
\hline Munc13-3 K0 & $2.02 \pm 0.20(17)$ & & \\
\hline WT (a) & $1.88 \pm 0.15(19)$ & Kruskal-Wallis test* & $p>0.05$ (a vs b) \\
\hline Munc13-2-3 DKO (b) & $2.00 \pm 0.20(18)$ & & $p<0.0001$ (b vs $c$ ) \\
\hline Munc13-1(1-451) (c) & $0.59 \pm 0.06(18)$ & & \\
\hline \multicolumn{4}{|c|}{ Cumulative EPSC amplitude (nA) } \\
\hline WT & $4.00 \pm 0.34(16)$ & Student's $t$ test & $p>0.05$ \\
\hline Munc13-2 K0 & $4.07 \pm 0.38(11)$ & & \\
\hline WT & $4.40 \pm 0.42(12)$ & Student's $t$ test & $p>0.05$ \\
\hline Munc13-3 K0 & $5.14 \pm 0.53(8)$ & & \\
\hline WT (a) & $6.32 \pm 0.44(15)$ & Kruskal-Wallis test* & $p>0.05(\mathrm{a}$ vs $\mathrm{b})$ \\
\hline Munc13-2-3 DKO (b) & $6.15 \pm 0.50(17)$ & & $p<0.0001$ (b vs c) \\
\hline Munc13-1(1-451) (c) & $2.72 \pm 0.24(16)$ & & \\
\hline \multicolumn{4}{|l|}{ P18-P21 synapse } \\
\hline \multicolumn{4}{|l|}{ eEPSC amplitude (nA) } \\
\hline WT & $4.94 \pm 0.40(21)$ & One-way ANOVA & $p>0.05$ \\
\hline Munc13-2 K0 & $5.78 \pm 0.52(23)$ & & \\
\hline Munc13-3 K0 & $5.96 \pm 0.71(14)$ & & \\
\hline WT (a) & $5.29 \pm 0.51(24)$ & Kruskal-Wallis test* & $p>0.05(\mathrm{a}$ vs $\mathrm{b})$ \\
\hline Munc13-2-3 DKO (b) & $5.80 \pm 0.49(24)$ & & $p<0.01$ (b vsc) \\
\hline Munc13-1(1-451) (c) & $2.57 \pm 0.32(15)$ & & \\
\hline \multicolumn{4}{|c|}{ Cumulative EPSC amplitude (nA) } \\
\hline WT & $20.08 \pm 2.76(16)$ & One-way ANOVA & $p>0.05$ \\
\hline Munc13-2 K0 & $20.64 \pm 2.07(18)$ & & \\
\hline Munc13-3 KO & $21.88 \pm 2.65(12)$ & & \\
\hline WT (a) & $26.48 \pm 2.01(22)$ & Kruskal-Wallis test* & $p>0.05$ (a vs b) \\
\hline Munc13-2-3 DKO (b) & $25.97 \pm 3.58(20)$ & & $p<0.001$ (b vs c) \\
\hline Munc13-1(1-451) (c) & $10.97 \pm 1.26(14)$ & & \\
\hline
\end{tabular}

*Kruskal-Wallis test with a post hoc Dunn's test to compare selected pairs.

both the young and mature age groups (P9-P11 synapse, DKO vs Munc13-1(1-451), $6.15 \pm 0.50$ vs $2.72 \pm 0.24 \mathrm{nA}, n=17$ vs $n=$ 16; P19-P21 synapse, DKO vs Munc13-1(1-451), $25.97 \pm 3.58$ vs $10.97 \pm 1.26 \mathrm{nA}, n=20$ vs $n=14$ ) (Fig. 5; Table 2). Analysis of the kinetics of release also demonstrated that perturbation of Munc13-1 function leads to changes in short-term plasticity kinetics. All in all, use of our dominant negative demonstrates that synaptic transmission and plasticity at the calyx of Held is primarily determined by Munc13-1 and does not use a Munc13independent pathway that has been reported in other sensory systems (Cooper et al., 2012).

The rate of calcium-dependent recovery from synaptic depression was enhanced in Munc13-2-3 DKO but not in Munc13-2 or Munc13-3 single KO background

It is well known that the calyx of Held can fire at high frequencies of up to $1 \mathrm{kHz}$ and that high-frequency stimulation causes an accumulation of residual calcium, which leads to calciumdependent recruitment mechanisms of vesicle pool refilling (Wang and Kaczmarek, 1998; Sakaba and Neher, 2001b; Hosoi et al., 2007). Efforts to understand the molecular mechanisms of calcium-dependent recruitment in CNS synapses have suggested that Munc13-1 and Munc13-2 differentially regulate calciumdependent recruitment (Rosenmund et al., 2002), whereas the role of Munc13-3 in calcium-dependent recruitment remains unknown. To determine whether the loss of Munc13-2 or Munc13-3 or Munc13-2 and Munc13-3 combined affected calcium-dependent recovery after high-frequency stimulation at the calyx of Held synapse, we performed afferent fiber stimula- tion at $300 \mathrm{~Hz}$, which has been shown to induce calciumdependent recovery effects in mice after the onset of hearing (Wang and Kaczmarek, 1998). Animals from the P9-P11 age group were excluded because the calyx/MNTB synapses cannot follow at $300 \mathrm{~Hz}$ frequency. Figure $6 A 1$ demonstrates the paired $300-\mathrm{Hz}$-train protocol we used, $30 \mathrm{AP}$ at $300 \mathrm{~Hz}$ (control train) to deplete the RRP and with interstimulus interval of $200 \mathrm{~ms}$ and then another $30 \mathrm{AP}$ at $300 \mathrm{~Hz}$ to test the RRP recovery (test train). The $200 \mathrm{~ms}$ time point was chosen because this is a reliable point as a screen to uncover differences in calcium-dependent recovery (Sakaba and Neher, 2003). To calculate the recovery rate, we measured the cumulative EPSC amplitude during the test train and normalized it to the cumulative EPSC amplitude in the control train (Yang et al., 2010). Figure 6A2 shows that, although single loss of Munc13-2 or Munc13-3 had no effect on total amount of RRP recovered, loss of both isoforms increased the total amount of RRP recovered compared with WT control (WT, $0.4511 \pm 0.00912, n=19 ;$ Munc13-2 KO, $0.4623 \pm 0.01229, n=$ 12 vs WT, $p>0.05$; Munc13-3 KO, $0.4384 \pm 0.01886, n=7$ vs $\mathrm{WT}, p>0.05$; Munc13-2-3 DKO, $0.5147 \pm 0.01167, n=17$ vs WT, $p<0.01)$. In addition, expression of the Munc13-1 $\mathrm{N}$-terminal dominant negative blocked the increase in the total RRP recovered in the Munc13-2-3 DKO background (Munc13$1(1-451), 0.4161 \pm 0.03496, n=7$ vs DKO, $p<0.01)$.

Because the combined loss of Munc13-2 and Munc13-3 resulted in an increased amount of recovered RRP at the $200 \mathrm{~ms}$ time point, we further calculated the calcium-dependent recovery time course (Fig. 6B1,B2). Our results show that the WT calcium-dependent recovery curve could be fitted by a double 
A1

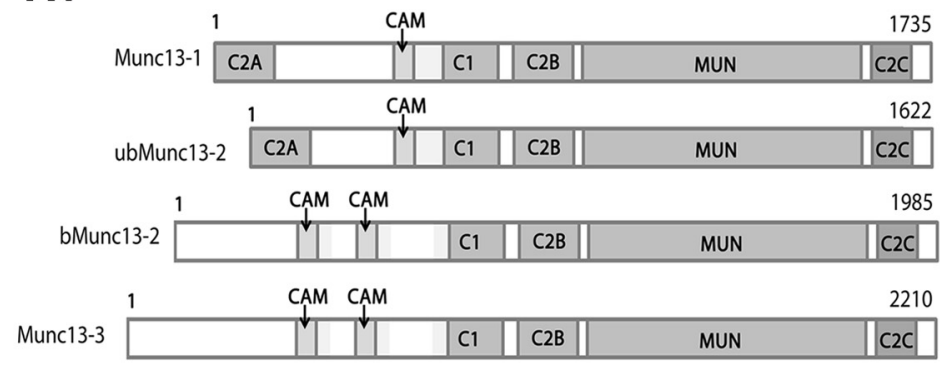

A2

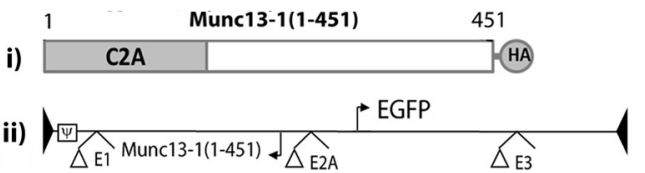

iii)

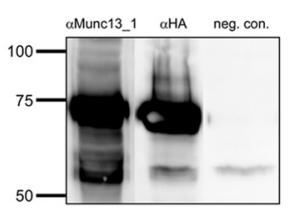

B1
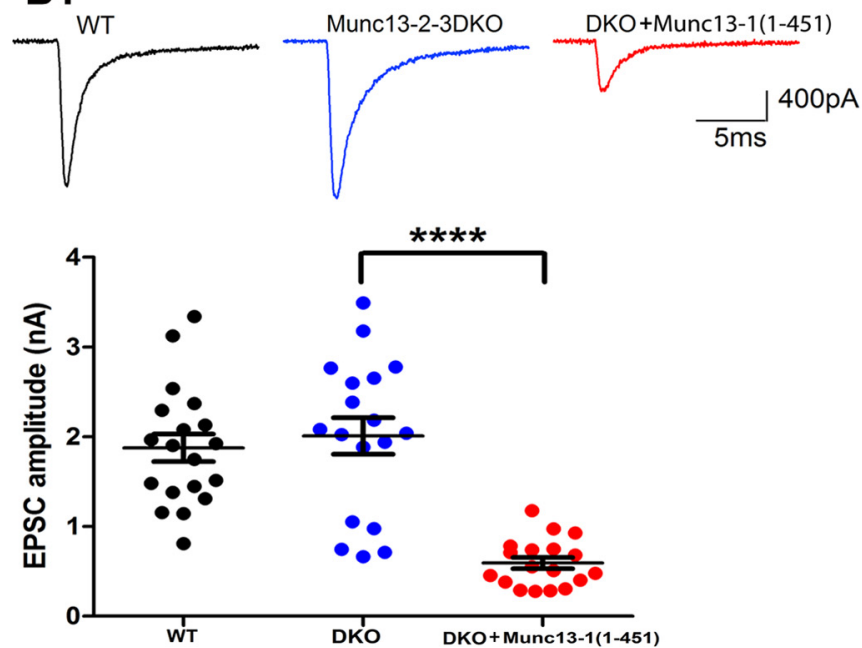

P9-P11

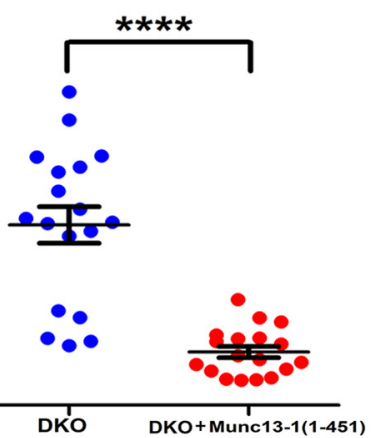

B2

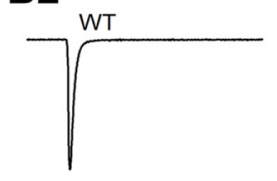

P18-P21
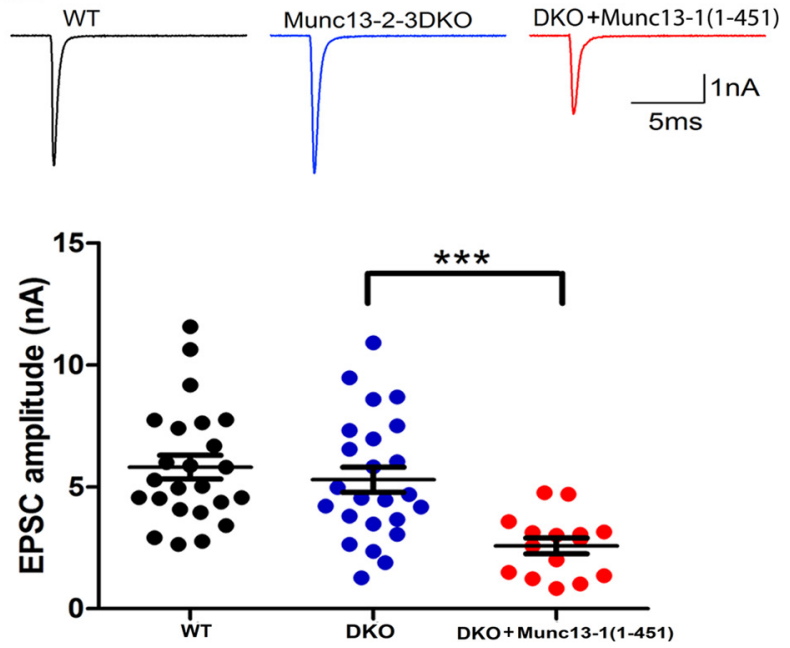

Figure 4. Munc13-1 is the dominant priming factor in the calyx of Held synapse, and the loss of both Munc13-2 and Munc13-3 does not affect synaptic transmission. A1, Domain structure of major Munc13 proteins. CAM, Calmodulin binding domain. Note that only Munc13-1 and ubMunc13-2 have C2A domain in the N terminal. A2i, Munc13-1(1-451) structure with HA tag. A2ii, rAd Munc13-1(1-451) virus structure; the black triangles represent the viral inverted terminal repeats, the packaging signal $\Psi$ is highlighted by the open box. A2iii, Western blot data showing that Munc13-1(1-451) was expressed from the virus. $\alpha$ Munc13_1, Antibody against Munc13-1; $\alpha$ HA, antibody against HA; neg.con, negative control. B1, Representative traces of single AP-evoked EPSC in WT synapse, Munc13-2-3 DK0 synapse, and Munc13-2-3 DK0 synapse expressing dominant-negative Munc13-1(1-451) in P9-P11 mice. The pool data are shown in the bottom panel. B2, Similar to $B 1$ but the EPSCs recorded from P18 -P21 mice. Data are presented as mean and SEM. ${ }^{* *} p<0.001,{ }^{* * * *} p<0.0001$, Kruskal-Wallis test with a posthoc Dunn's test to compare selected pairs.

exponential with an average time constant of fast time constant $\left(\tau_{1}\right)$ of $116 \mathrm{~ms}$ and slow time constant $\left(\tau_{2}\right)$ of $3.6 \mathrm{~s}$, with the relative contributions being 28 and $72 \%$, respectively, for the two components, similar to the result from Wang and Kaczmarek (1998). However, Munc13-2-3 DKO synapses exhibited a faster recovery, with $\tau_{2}$ being significantly faster compared with WT (110 $\mathrm{ms} \tau_{1}$ and $2.8 \mathrm{~s} \tau_{2}$ vs $116 \mathrm{~ms} \tau_{1}$ and $3.6 \mathrm{~s} \tau_{2}$; for $\tau_{2}$, WT vs DKO, $n=8$ vs $n=10, p<0.01$, Student's unpaired $t$ test) with a slight change in the relative amplitudes of the time constants (38\% $\tau_{1}$ and $62 \% \tau_{2}$ DKO vs $28 \% \tau_{1}$ and $72 \% \tau_{2} \mathrm{WT}$ ) (Fig. 6B2). Based on these results, it can be concluded that the combined loss of Munc13-2 and Munc13-3 result in an enhancement of calcium-dependent recovery. Furthermore, because the Munc13-1 dominant-negative blocks this enhancement of calcium-dependent recovery, we conclude that this enhancement relies on a Munc13-1-dependent mechanism.

\section{Munc13-1 levels are unchanged in the Munc13-2-3 \\ DKO calyx}

To determine whether the enhancement of calcium-dependent recovery in the Munc13-2-3 DKO synapses was attributable to a compensatory increase in global Munc13-1 expression, we performed a semiquantitative measurement by using Western blot analysis in the isolated MNTB from (P18-P19) WT and
Munc13-2-3 DKO auditory brainstems. Using a Munc13-1specific antibody, we then compared relative signals of Munc13-1 from the DKO and WT samples (Fig. 7). We then normalized the Munc13-1 signal relative to actin on the immunoblots and normalized the DKO signal to the WT signal. Figure $7 B$ revealed no difference between the DKO and WT samples (0.985 \pm 0.075 , $n=3$ ). Based on the comparable Munc13-1expression levels in WT and DKO samples, a simple mechanism of upregulation of Munc13-1 in the DKO background cannot account for the increase in calcium-dependent recovery but rather points to differences between Munc13-1 and the other Munc13 isoforms in the regulation of calcium-dependent recovery.

Use of long depolarizations to quantify the total RRP size and composition reveal changes in the ratio of the fast pool to slow pool with small reduction of the total RRP size in the Munc13-2-3 DKO background

Because the combined loss of Munc13-2 and Munc13-3 led to an increase in calcium-dependent recovery, it became important to understand at a more quantitative level whether there was a change in the regulation of pool dynamics at the calyx. In the immature calyx of Held synapse of rats and mice but not in the functionally mature calyx of Held, it has been shown that, using $0.5 \mathrm{~mm}$ EGTA, one can separate the releasable pool clearly into a 


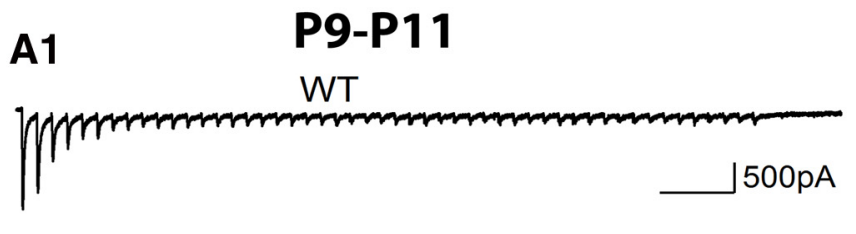

Munc13-2-3DKO

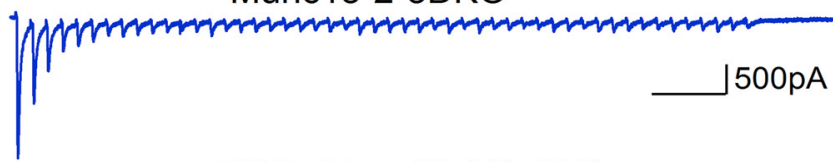

DKO+Munc13-1 (1-451)

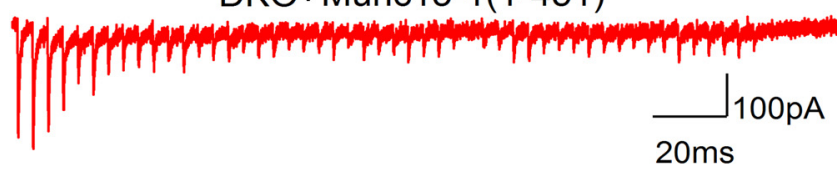

B1
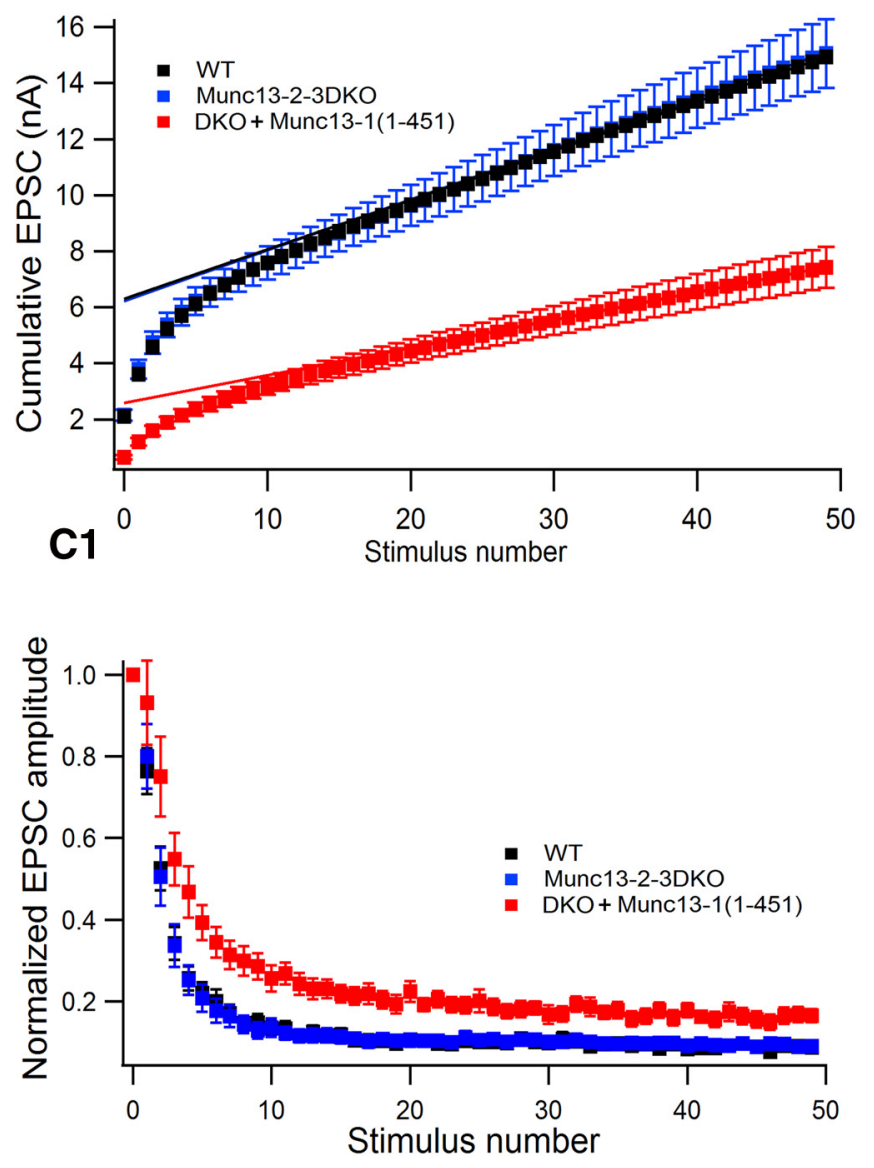

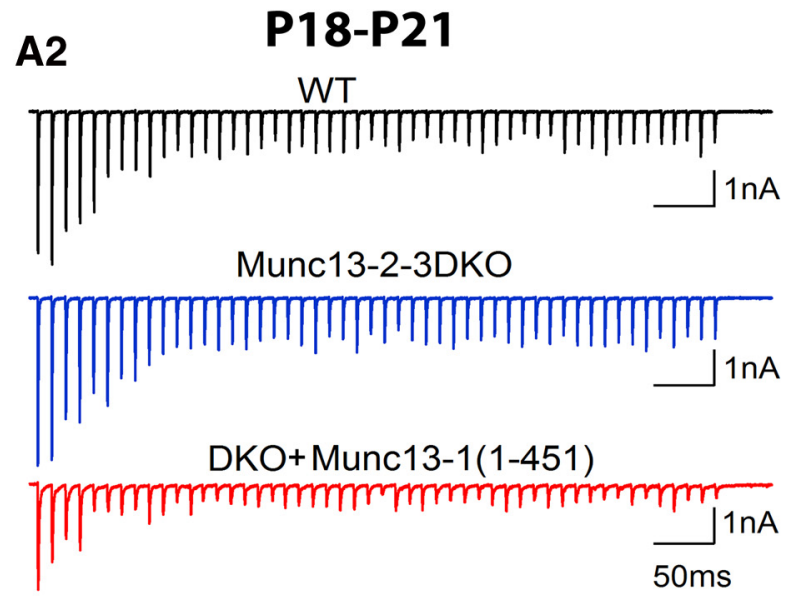

B2
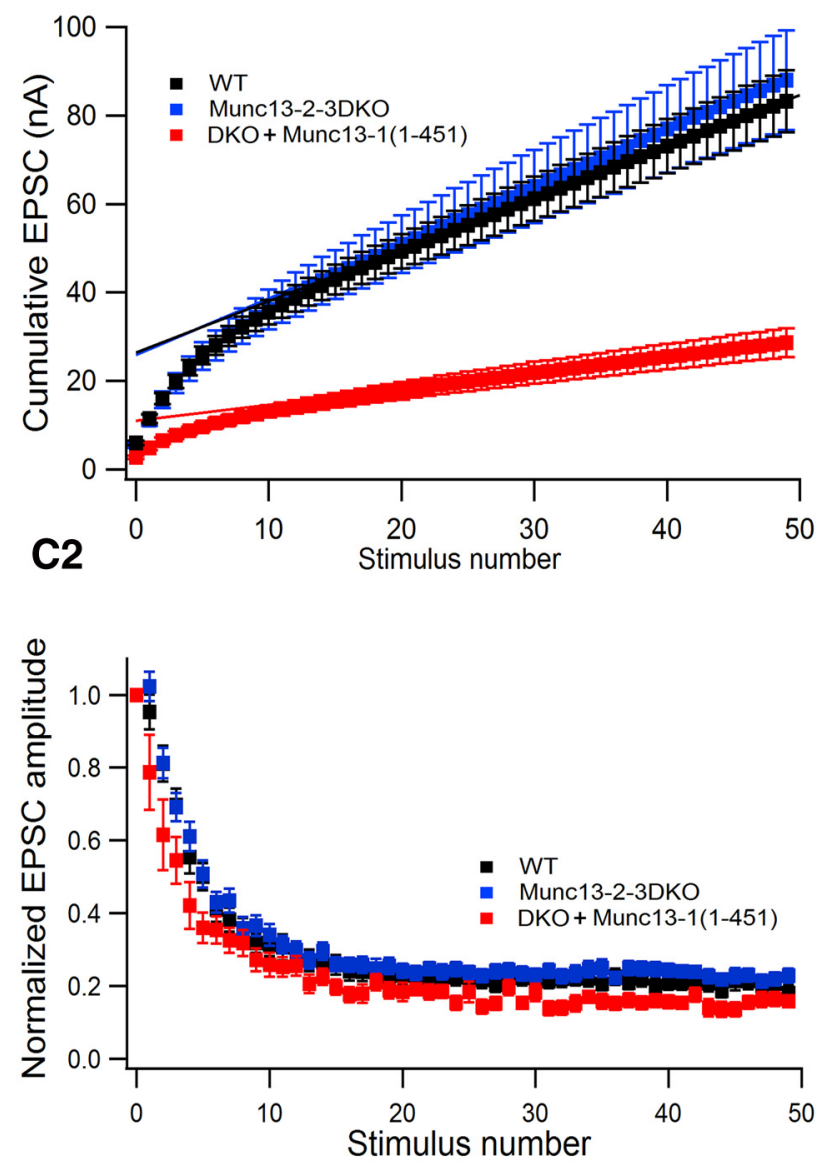

Figure 5. Short-term plasticity at the calyx of Held synapse is affected by disturbing the function of Munc13-1 and not affected by the loss of both Munc13-2 and Munc $13-3$. A1, $A$ 2, Representative traces of $100 \mathrm{~Hz}$ train stimulus (50 APs) evoked EPSC from WT synapse, Munc13-2-3DK0 synapse, and Munc13-2-3 DK0 synapse expressing dominant-negative Munc13-1(1-451) in P9-P11 mice (A1) and P18 -P21 mice (A2).B1, B2, Cumulative EPSC amplitudes for $100 \mathrm{~Hz}$ stimulation from P9 -P11 mice (B1) and P18 -P21 mice (B2). Data points from the 30 th to 50 th EPSCs were fitted with a straight line and back-extrapolated to time 0 to estimate the releasable vesicles pool. C1, C2, Summary plot of normalized relative EPSC amplitude to the initial EPSC amplitude during a train of 100 $\mathrm{Hz}$ stimulus, against the stimulus numbers. Data are presented as mean and SEM.

fast releasing pool and a slowly releasing pool, with both subpools comprising similar numbers of vesicles (Neher and Sakaba, 2001a; Sakaba and Neher, 2001a; Wang et al., 2008). Furthermore, it has been shown that the fast releasing pool contributes mainly to synchronous release, whereas the slowly releasing pool contributes to asynchronous release during high-frequency train stimulation (Sakaba, 2006). Although we found that the RRP size was unchanged as measured by afferent fiber stimulation at both $100 \mathrm{~Hz}$ (Fig. 5) and $300 \mathrm{~Hz}$ (data not shown) in the WT and Munc13-2-3 DKO terminals, it is known that afferent fiber stimulation has potential issues in accurately reporting the total RRP size because of its inability to accurately account for the slow pool component of the RRP and vesicle recruitment kinetics (Neher and Sakaba, 2008; Lee et al., 2012). Thus, to accurately examine 
A1

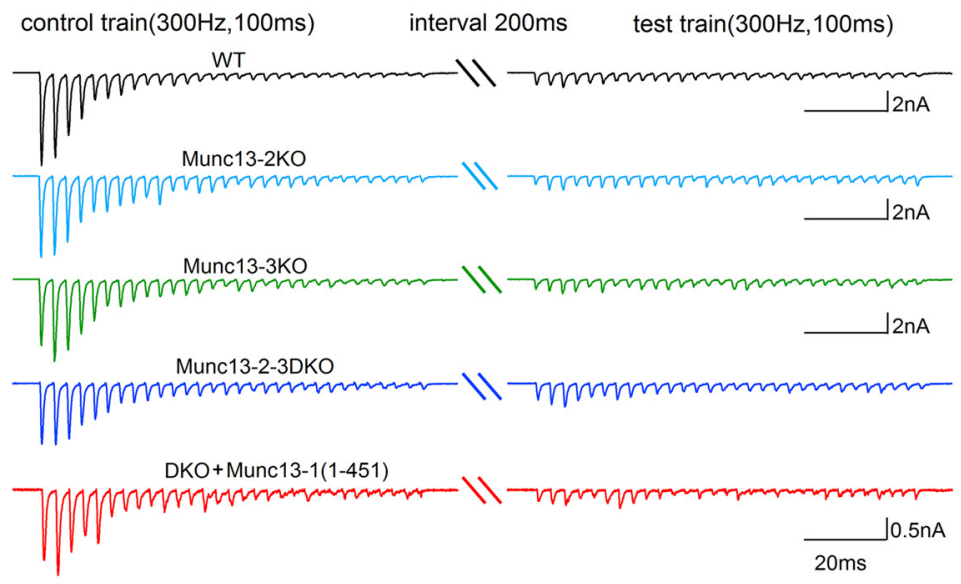

A2

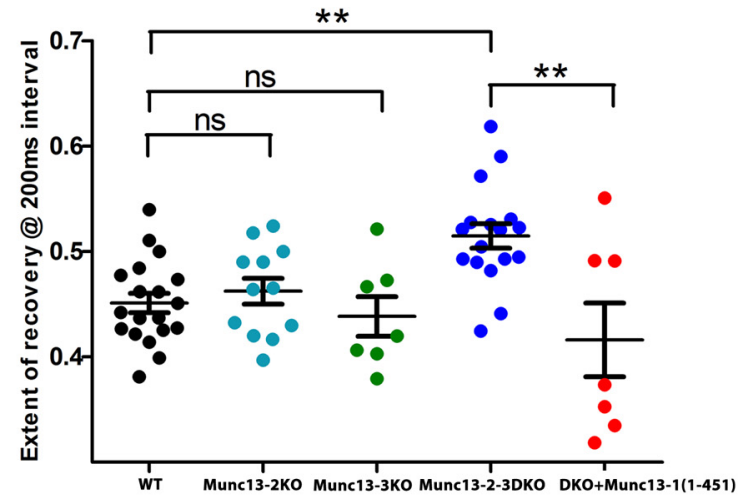

B1

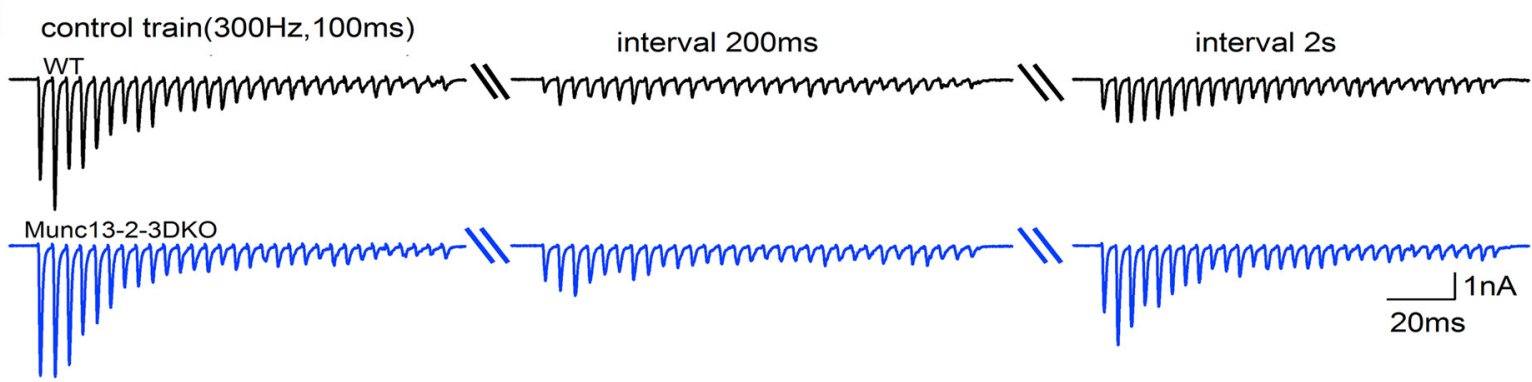

B2

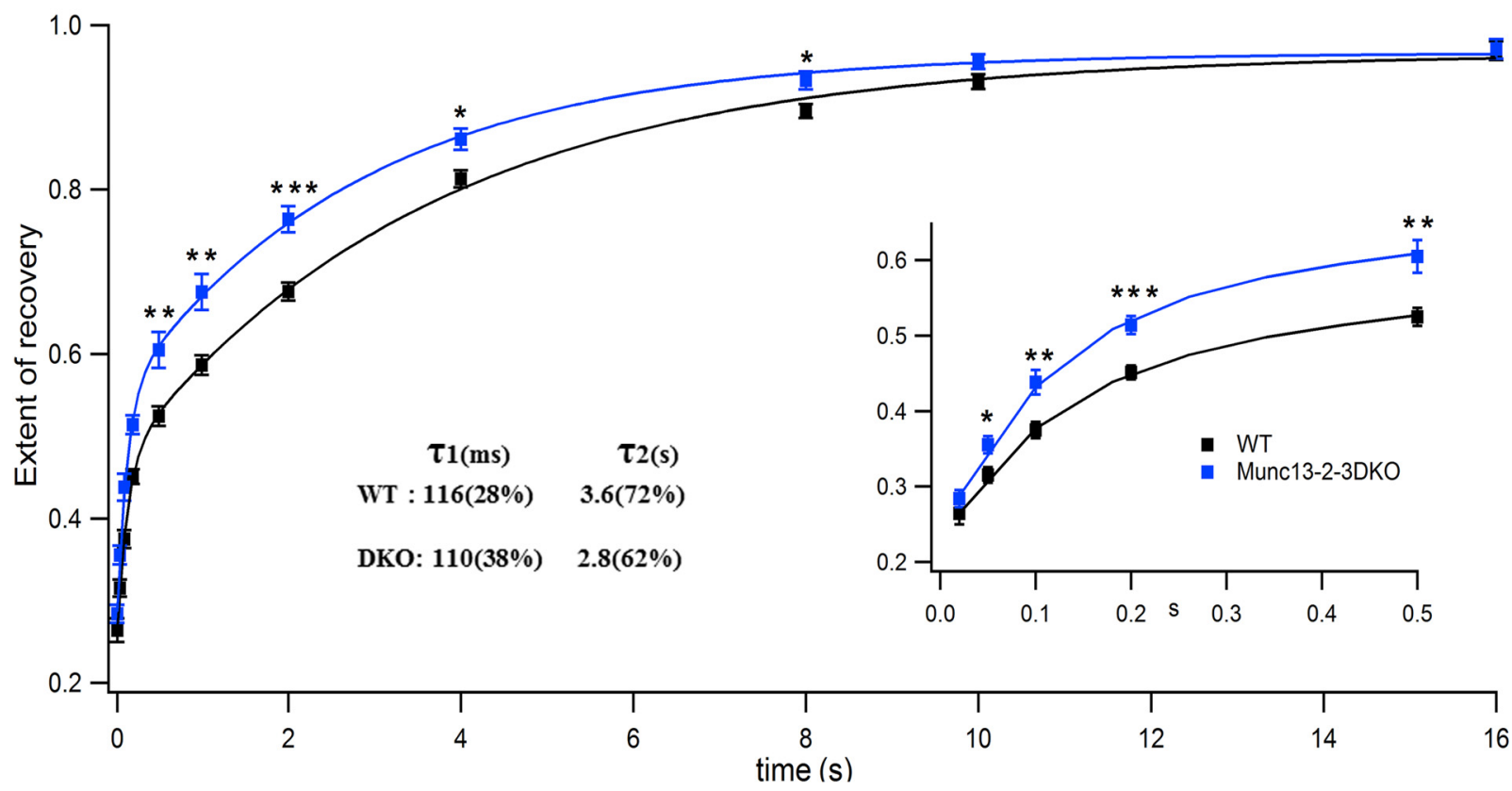

Figure 6. Loss of both Munc13-2 and Munc13-3 enhances calcium-dependent recovery measured with $300 \mathrm{~Hz}$ trains stimulus at the calyx of Held synapse, and the enhancement can be reduced by disturbing the function of Munc13-1.A, A300 Hz, $100 \mathrm{~ms}$ train stimulus was applied as control, and after an interval of $200 \mathrm{~ms}$, the same train (test train) was applied to test the recovery of synaptic vesicles pool. A1, EPSC in response to double $300 \mathrm{~Hz}$ train stimulus with $200 \mathrm{~ms}$ intervals in WT (black), Munc13-2 KO (light blue), Munc13-3 KO (green), Munc13-2-3 DKO (deep blue), and Munc13-2-3 DKO synapses expressed with Munc13-1(1-451) virus (red) from P18-P21 mice. A2, Summary data for cumulative EPSCs recovery from $200 \mathrm{~ms}$ interval. These data were from the double $300 \mathrm{~Hz}$ train stimulation protocol shown in A1; the cumulative EPSCs for the test train were divided by the cumulative EPSCs from the control train as recovery extent. WT versus DKO, $p<0.01$; WT versus Munc13-2 K0, $p>0.05 ;$ WT versus Munc13-3 K0, $p>$ 0.05 ; DKO versus DKO + Munc13-1(1-451), $p<0.01$; Kruskal-Wallis test with a post hoc Dunn's test to compare selected pairs. WT, $n=19 ; \mathrm{DKO}, n=17$; Munc13-2 KO, $n=12 ;$ Munc13-3 K0, $n=7$; DKO + Munc13-1(1-451), $n=7$. Because Munc13-2 WT and Munc13-2-3 WT have similar responses, here we compare the data to Munc13-2-3 WT. B1, EPSCs in response to double $300 \mathrm{~Hz}$ train stimulation with different time intervals in WT (black) and Munc13-2-3 DKO (blue) synapses from P18-P21 mice. B2, Summary data for cumulative EPSCs recovery from different intervals. These data were from the double 300 $\mathrm{Hz}$ train stimulation protocol shown in $\mathbf{B 1}$; the cumulative EPSCs for the second train were normalized to the cumulative EPSCs for the control train as recovery extent. The recovery extent were plotted against the different time intervals. The recovery time course was fitted with a double-exponential curve. The inset shows a magnified view for the first five time intervals. At least eight cells for each interval. The data are presented as mean and SEM. ${ }^{*} p<0.05,{ }^{* *} p<0.01,{ }^{* * *} p<0.001$, Student's unpaired $t$ test. 
A

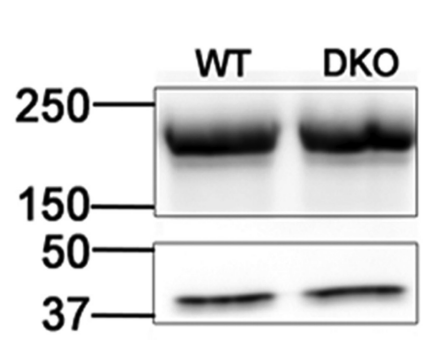

B DKO/WT

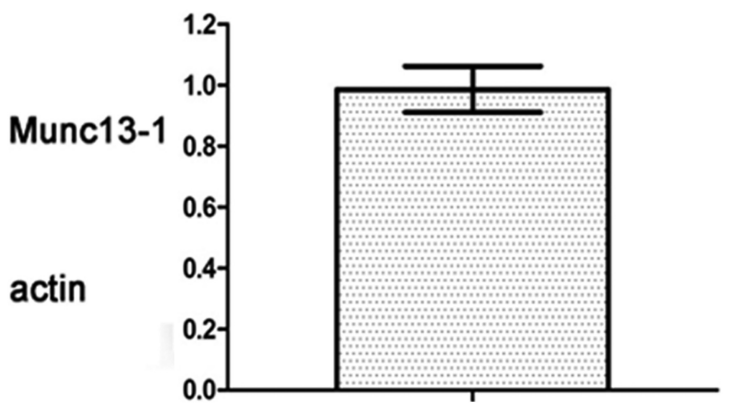

Figure 7. Munc13-1 protein expression level is not changed by loss of both Munc13-2 and Munc13-3. A, Western blot detection of Munc13-1 protein expression levels in WT and DKO calyx/MNTB region using Munc13-1 antibody. $\beta$-Actin levels were used as a control for normalization. $\boldsymbol{B}$, Normalized Munc13-1 signal in DK0 calyces divided by normalized Munc13-1 signal in WT calyces. Munc13 signals were first normalized by normalizing to actin signal levels. $n=3$. Samples were combined from $n=3$ animals at P19.

A

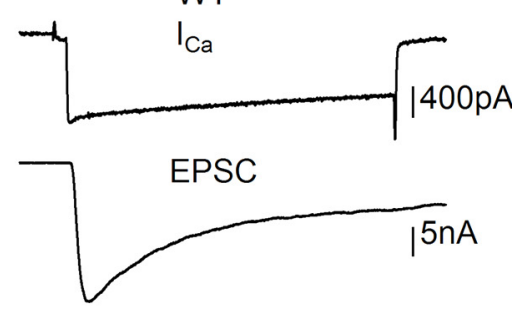

B1

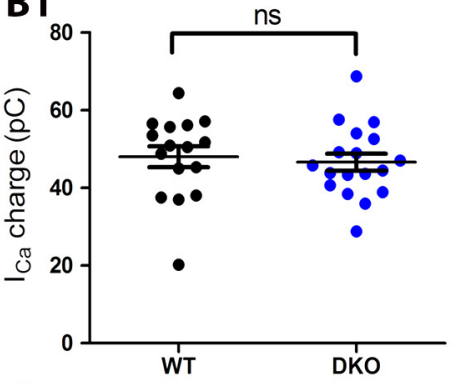

C

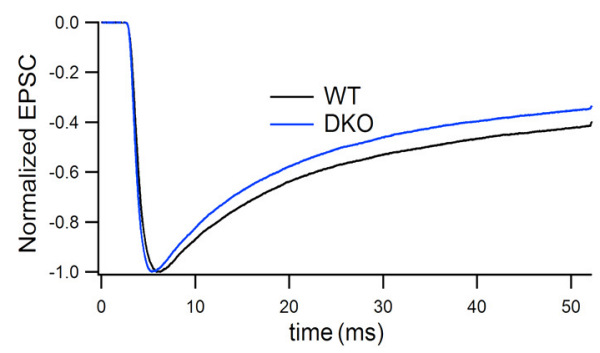

A2

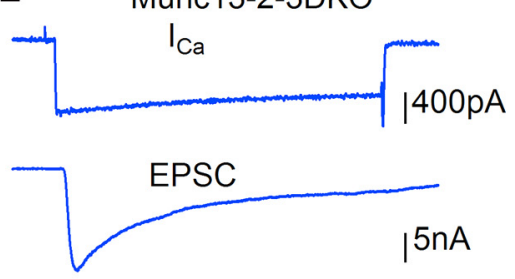

B2

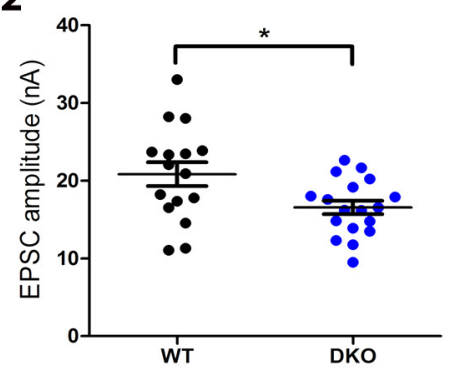

Figure 8. Pair recording showed that EPSCs evoked by long presynaptic depolarization had smaller amplitude and less slow release in DKO calyces. Calyces and the principal cells of the MNTB were simultaneously voltage clamped at -80 and $-60 \mathrm{mV}$, respectively. The presynaptic calyces were stimulated by long depolarization. Stimulation protocol was -80 to $+70 \mathrm{mV}$ for $2 \mathrm{~ms}$, followed by $50 \mathrm{~ms}$ at $0 \mathrm{mV}$ and then back to $-80 \mathrm{mV}$. $\boldsymbol{A 1}, \boldsymbol{A 2}$, Sample traces for calcium current and EPSC evoked by long depolarization from P9 to P11 WT (A1) and Munc13-2-3 DK0 mice (A2). Traces shown from top to bottom are presynaptic calcium current, EPSC. B1, B2, Scatter plot data for calcium current charge integrals (B1) and EPSC amplitudes (B2). The presynaptic calcium current was integrated from its onset of the influx to the end of the depolarization as calcium current charge integral. Each point represents one synapse. Data are shown as mean and SEM. ${ }^{*} p<0.05$, Student's unpaired $t$ test. C, Normalized EPSC to the peak amplitude. The black trace is from average of 16 WT calyces, and the blue trace is from average of 18 DKO calyces. Note that DKO calyces had less slow release in the late stimulation. The right panel shows a magnified view of the rise phase of the normalized EPSCs. Note that DKO calyces had a slightly faster rise time than WT calyces.

whether the loss of both Munc13-2 and Munc13-3 affected the total RRP size and kinetics of release at the calyx of Held, the presynaptic terminals from $\mathrm{P} 9-\mathrm{P} 11$ WT and Munc13-2-3 DKO mice were voltage clamped at $-80 \mathrm{mV}$ and stimulated with a $50 \mathrm{~ms}$ depolarization during which EPSCs from the postsynaptic MNTB were simultaneously recorded (Sakaba and Neher, 2001a) (Fig. 8A1,A2). Using this long depolarization protocol, we found that the resultant EPSC amplitudes from the Munc13-2-3 DKO calyces were on average $20 \%$ smaller compared with WT amplitudes (16.55 \pm 0.857 vs $20.84 \pm 1.526$ nA; $n=18$ vs $16 ; p<0.05$ ), although the calcium current charge was unchanged (Fig. 8B1,B2). To determine whether there were any changes in the kinetics of release, we then normalized the EPSC waveforms. Analysis of the normalized EPSC waveforms revealed that EPSC from Munc13-2-3 DKO synapse has faster rise time kinetics and less delayed release compared with WT calyces (Fig. 8C1,C2).

Because there were changes in the EPSC waveforms, which indicated that loss of Munc13-2-3 affects RRP dynamics, we further quantified the kinetics of release and size of the RRP using a deconvolution analysis routine of the resulting EPSC that takes into account the glutamate spillover component (Neher and Sakaba, 2001a,b). Deconvolution analysis revealed that the peak release rates were not significantly different between WT and Munc13-2-3 DKO calyces (WT, $725 \pm 70$ vesicles $/ \mathrm{ms}, n=15 ; \mathrm{DKO}, 695 \pm$ 52 vesicles/ms, $n=17$; $p>0.05$ ) but revealed a reduction in the delayed release (slow pool component) and a faster rise time to peak release rates, which is in agreement with the EPSC waveform (Fig. $9 A 2 b, A 2 c)$. To determine the RRP size, we integrated the peak release rate and corrected for ongoing recruitment of vesicles (Neher and Sakaba, 2001a,b). The pool size was reduced by $\sim 25 \%$ in Munc13-2-3 DKO calyces compared with that of WTs (WT, $2709 \pm 226$ and DKO, $2050 \pm 136.4$ vesicles; $n=15$ and $n=17 ; p<0.05$ ) (Fig. 9B1,C1).

Subsequently, to analyze the size of the fast pool and slow pool components of the RRP, the integrated cumulative release rates were fitted with a doubleexponential curve (Fig. 9B1) (Neher and Sakaba, 2001a,b). Interestingly, our analysis revealed that the total amount of vesicles in the fast pool was almost identical (WT, $1454 \pm 114.9$ vesicles, $n=15$; DKO, $1246 \pm 72.0$ vesicles, $n=17$ ), but there was a selective reduction in the slow pool 


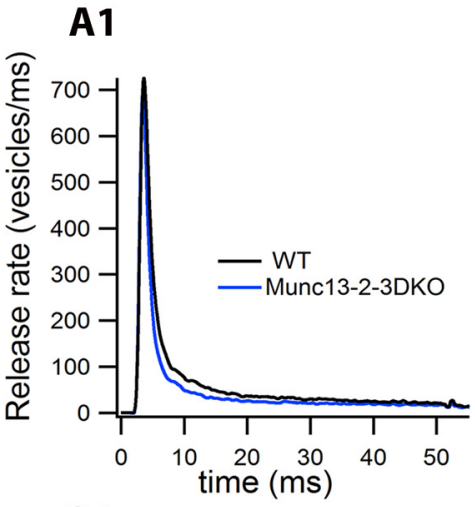

B1

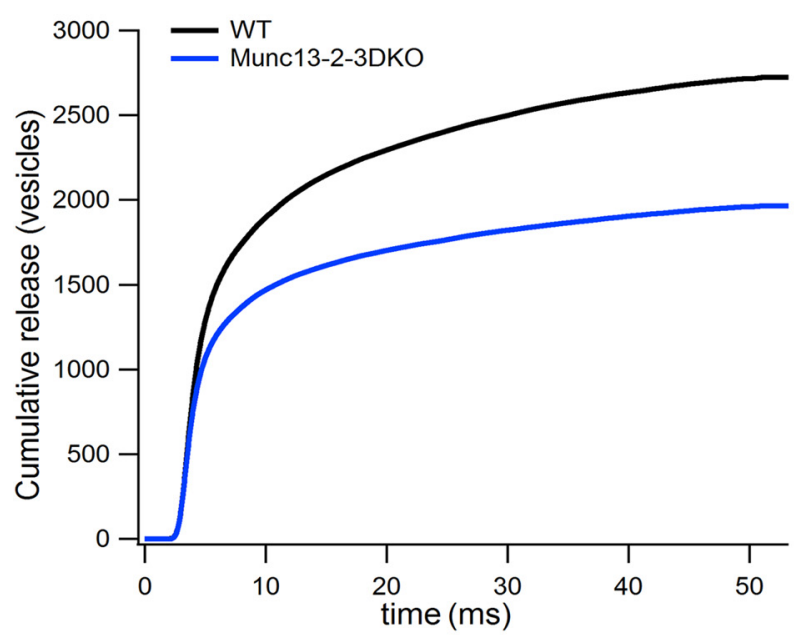

C1

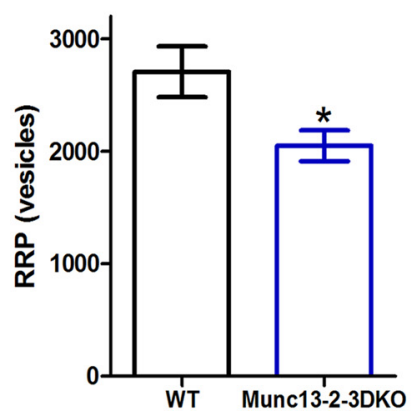

C2

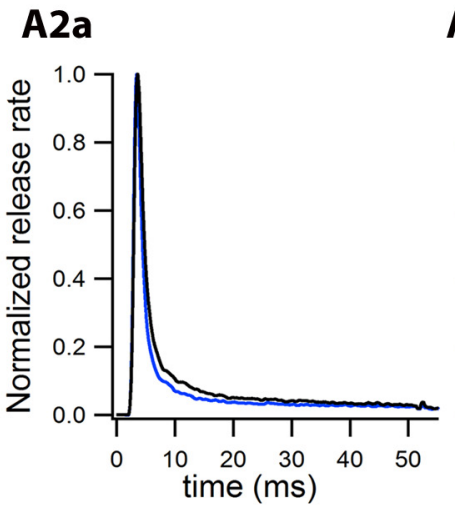

A2b

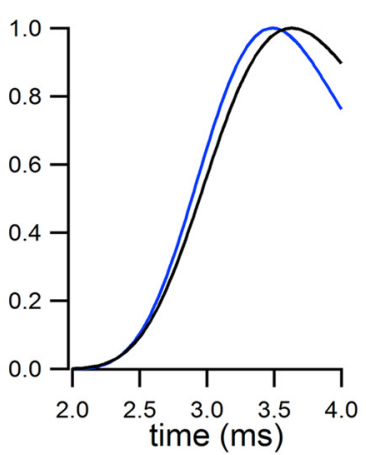

A2c

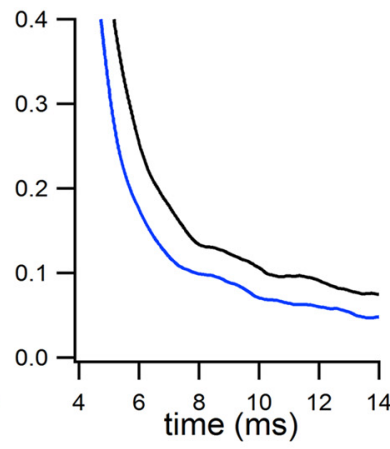

B2

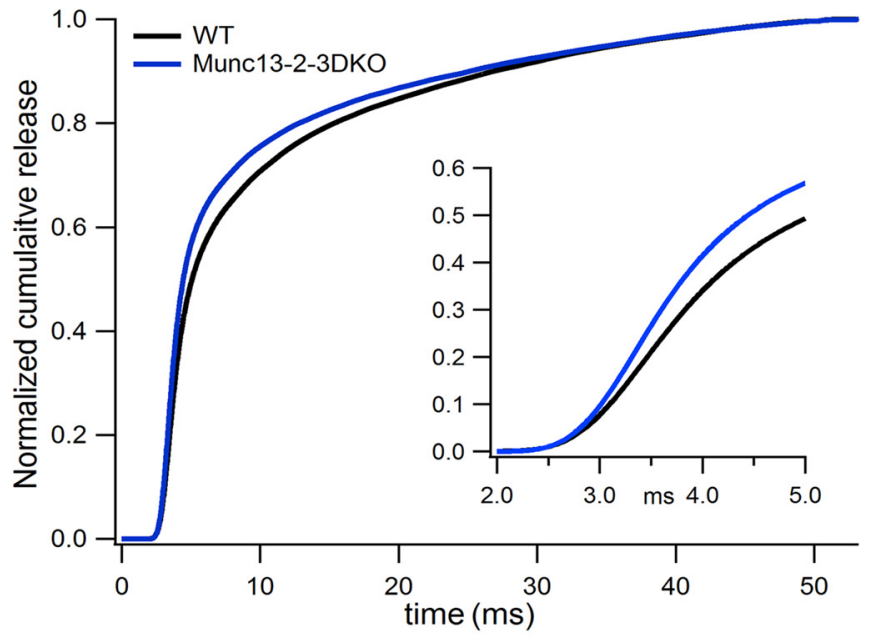

C3

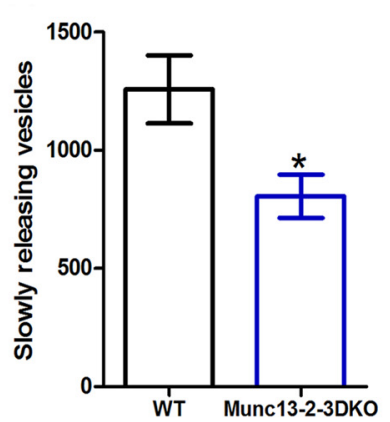

C4

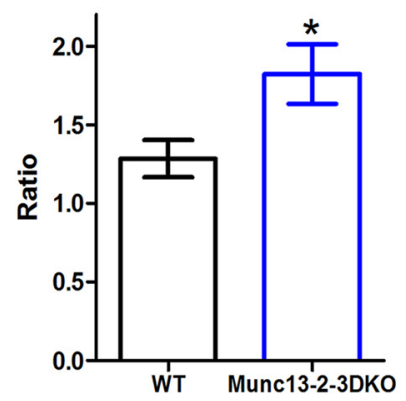

Figure 9. Deconvolution analysis from pair recording data showed that RRP was reduced in the DKO calyces and selectively reduced in slowly releasing vesicles pool without changing the fast releasing vesicles pool. $\boldsymbol{A} \mathbf{1}, \boldsymbol{A 2}$, Average release rate $(\boldsymbol{A} \mathbf{1})$ and normalized peak release rate $(\boldsymbol{A} \mathbf{2})$. $\boldsymbol{A} \mathbf{2} \boldsymbol{b}$ and $\boldsymbol{A} \mathbf{2}$ show a magnified view of the rising phase and falling phase of the normalized peak release rate, respectively. From the normalized release rate, notice that DKO calyces had slightly faster rising time and less slow component in the late release. The black trace is from an average of 15 WT calyces, and the blue trace is from an average of 17 DK0 calyces. $\boldsymbol{B} 1, \boldsymbol{B 2}$, Trace of averaged cumulative release (B1) and normalized cumulative release (B2). The inset in $\boldsymbol{B 2}$ shows a magnified view for the first $3 \mathrm{~ms}$ release. C, Summary data for RRP (C1), fast releasing vesicles (C2), slowly releasing vesicles (C3), and ratio of fast releasing vesicles to slowly releasing vesicles (C4). Data are shown as mean and SEM. ${ }^{*} p<0.05$, Student's unpaired $t$ test.

size in the Munc13-2-3 DKO calyces (WT, $1258 \pm 144$ vesicles, $n=15$; DKO, $806 \pm 91$ vesicles, $n=17 ; p<0.05$ ) (Fig. 9C2,C3). This selective loss of the slow pool component was reflected in a $40 \%$ increase in the ratio of fast pool to slow pool components of the RRP in the Munc13-2-3 DKO synapse compared with WT (WT, $1.284 \pm 0.1184, n=15$; DKO, $1.823 \pm 0.1891, n=17 ; p<$ 0.05 ) (Fig. 9C4). Finally, normalization of the cumulative release rates revealed that Munc13-2-3 DKO synapses exhibited a slight increase in the rate of release compared with WT synapses (Fig. 7B2). Together, the data provide evidence that the different
Munc13 isoforms have differential abilities in slow pool to fast pool conversion, a process that regulates the availability of vesicles for synchronous transmission. The similar size of the fast releasing pool in the WT and DKO calyces is consistent with our fiber stimulation data because the fast releasing pools are mainly responsible for AP-evoked release.

\section{Discussion}

It has been hypothesized that Munc13-2 and Munc13-3 isoforms act in conjunction with Munc13-1 to modulate synaptic plastic- 
ity (Augustin et al., 1999b; Rosenmund et al., 2002). However, Munc13-2 or Munc13-3 isoforms are either functionally dispensable or their loss causes increases in frequency-dependent facilitation at different synapses (Augustin et al., 2001; Bao et al., 2010; Breustedt et al., 2010). These findings contradict predictions of Munc13-2 function based on the observation that ubMunc13-2 overexpression resulted in frequency-dependent facilitation (Rosenmund et al., 2002). Using the calyx of Held as a model system to address this conundrum, we found that Munc13-1, ubMunc13-2, and Munc13-3 are expressed at the calyx (Figs. 1-3), with Munc13-1 being the most highly expressed isoform at the calyx of Held and the only isoform highly colocalized to the AZ marker Bassoon (Fig. 2). We find that the combined loss of both Munc13-2 and Munc13-3 results in the following: (1) an increase in the rate of calcium-dependent recovery (Fig. 6); (2) no change in the number of vesicles available for AP-evoked release (Fig. 5); (3) a reduction in the total RRP (comprising vesicles involved in both AP-evoked and delayed release) (Fig. 9); and (4) a specific reduction in the slow pool component of the total RRP (Fig. 9). Finally, we demonstrate that these effects on synaptic vesicle pool dynamics were Munc13-1 dependent because overexpression of dominant-negative Munc13-1 resulted in a significant reduction in the AP-evoked RRP size and blocked the enhancement of calcium-dependent recovery (Figs. 4-6). Together, these results lead to the conclusion that the Munc13 isoforms differentially regulate calcium-dependent recovery and slow to fast pool conversion in central synapses.

\section{Munc13 isoform expression and localization at the calyx}

Past studies have suggested that two isoforms of Munc13 are expressed at conventional synapses in the CNS, namely Munc13-1 in combination with Munc13-2 or Munc13-3 (Augustin et al., 1999a,b, 2001; Varoqueaux et al., 2002). Here we demonstrate using Munc13 isoform-specific antibodies and Munc13-XFP-tagged mouse strains that the calyx expresses three Munc13 isoforms: Munc13-1, ubMunc13-2, and Munc13-3 (Figs. 1-3). However, it cannot be excluded with the experimental conditions used in this study that bMunc13-2 may be expressed but not detectable; it should be noted that ubMunc13-3 and bMunc13-2 partition at different types of synapses in the retina (Cooper et al., 2012). Furthermore, the ubMunc13-2 and bMunc13-2 splice variants share identical C termini (Augustin et al., 1999b), and thus the Munc13-2-EYFP animals cannot be used to distinguish the two different splice variants (Cooper et al., 2012). Regardless, the Munc13-XFP mice will be extremely useful for elucidating Munc13 expression patterns.

Through quantitation of the Munc13-XFP signals (Fig. 3; Table 1), we show that Munc13-1 is the dominant isoform at the calyx regardless of the developmental stage analyzed and most abundantly localized to the AZ. Furthermore, Munc13-1 exhibited a twofold greater mean area of colocalization with Bassoon compared with Munc13-2 and Munc13-3 (Fig. 3; Table 1). High expression levels and tight spatial association with the AZ marker Bassoon may enable Munc13-1 to compensate for loss of any other Munc13 isoforms, which may explain the lack of drastic phenotypic changes in Munc13-2 and Munc13-3 KO mice. We predict that, at synapses in which Munc13-2 or Munc13-3 are functionally dispensable (Augustin et al., 1999a, 2001; Rosenmund et al., 2002; Varoqueaux et al., 2002; Bao et al., 2010; Breustedt et al., 2010), Munc13-1 is highly expressed and functionally self-sufficient. Conversely, in synapses in which loss of Munc13-2 or Munc13-3 affects synaptic transmission (Rosenmund et al., 2002; Bao et al., 2010; Breustedt et al., 2010), Munc13-1 may be expressed at insufficient levels to compensate for the loss of other Munc13 isoforms. The viability of Munc13-1 heterozygote-Munc13-2/3 DKO animals (Varoqueaux et al., 2002) may indicate that Munc13-1 concentrations must exceed a critical threshold to sustain adequate synaptic transmission for brain function.

Our quantitative immunohistochemistry data show that Munc13 isoforms are differentially distributed with respect to Bassoon (Fig. 3) and indicate that they likely use distinct mechanisms of synaptic targeting within a synapse. It is known that interactions between the Munc13-1 C2A domain and RIM1 are critical for targeting Munc13-1 to the AZ (Betz et al., 2001; Andrews-Zwilling et al., 2006) and that these C2A interactions with other AZ proteins are critical for synaptic transmission (Betz et al., 2001; Dulubova et al., 2005; Wang et al., 2009). However, it was found that Munc13-3, which lacks a C2A domain, was occasionally localized to the AZ, although with less efficiency and lesser degree of colocalization with Bassoon compared with Munc13-1 (Fig. 3; Table 2). Recently, Munc13-3 has been identified as part of the calcium channel proteome (Müller et al., 2010), which supports the hypothesis of alternative AZ targeting, although our data (Fig. 3) indicate that alternative C2Aindependent mechanisms for AZ targeting are less effective than those AZ targeting mechanisms used by Munc13-1. One candidate domain maybe the MUN domain because it interacts with syntaxin and the SNARE complex and is structurally related to other vesicle tethering factors (Betz et al., 1997; Guan et al., 2008; Li et al., 2011). Although ubMunc13-2 possesses a C2A domain but is not as abundantly colocalized with Bassoon as Munc13-1, this suggests that $\mathrm{C} 2 \mathrm{~A}$-dependent targeting mechanisms may be differentially regulated between the Munc13 isoforms.

\section{Munc13 isoforms and regulation of RRP dynamics}

Our fiber stimulation data (Fig. 4) demonstrate that the number of vesicles in the RRP available for AP-evoked release in Munc132/3 DKO calyces were not significantly different from WT controls. However, paired recording with long depolarizations (Fig. 8 ), which measures total vesicles that can be released by $\mathrm{Ca}^{2+}$ in the RRP, revealed a 25\% reduction in total RRP size in Munc13$2 / 3$ DKO calyces. More importantly, a selective loss in the delayed component of release was found in conjunction with a faster rise time of the EPSC (Figs. 8, 9), indicating that Munc13 isoforms differ in their regulation of the RRP dynamics. Previous studies demonstrated that Munc13-1 interacts with molecules involved in AZ organization (Betz et al., 2001; Dulubova et al., 2005; Wang et al., 2009; Limbach et al., 2011) and leads to the hypothesis that Munc13-1 plays a role in positional priming, the process of bringing synaptic vesicles in close proximity to calcium channels at the AZ in addition to other molecules in mammalian synapses (Sakaba et al., 2005; Hosoi et al., 2007; Young and Neher, 2009; Yang et al., 2010). Our combined electrophysiological (Figs. 4-6, 8,9 ) and morphological (Fig. 3) data support the hypothesis that Munc13-1 contributes to both molecular and positional priming. In this scenario, Munc13-1 primes vesicles in closer proximity on average to calcium channels than Munc13-2 or Munc13-3. Support for this interpretation of increased tight channel-vesicle coupling within the RRP comes from our data that demonstrated the following: (1) faster EPSC rise time kinetics and a decrease in decay time in the resultant ESPC from the long depolarization in the Munc13-2/3 DKO background (Fig. 7); (2) similar fast pool component size between the Munc13-2/3 DKO and WT (Fig. 8); (3) an increase in the ratio of fast pool/slow pool components in the Munc13-2/3 DKO (Fig. 8); (4) no change in the measurable RRP available for AP-evoked release (Fig. 5); and (5) Munc13-1 
being the only isoform highly colocalized with the AZ marker Bassoon (Fig. 3). We postulate that synaptic vesicles in the RRP of Munc13-2/3 DKO calyces would preferentially exist in the fast pool, because they would exclusively undergo Munc13-1dependent reactions within close proximity to calcium channels, thus resulting in no reduction in the AP-evoked RRP. However, in WT calyces, additional interactions with Munc13-2 and Munc13-3 at greater distances from the AZ would constrain the conversion of vesicles from slow to fast pools of the RRP and contribute to a larger slow component in paired recording. It should be noted that recent work has shown that these slow pool vesicles can be rapidly converted to fast pool vesicles through two independent mechanisms (one dependent on calmodulin and one independent of calmodulin) that regulate positional priming (Lee et al., 2010; 2012) and suggests that sequence differences in Munc13 isoforms may be mechanistically responsible for positional priming in addition to the Munc13-1 C2A domain.

Our analysis of calcium-dependent recovery kinetics in the Munc13-2/3 DKO revealed that Munc13-1-regulated calciumdependent recovery is different from the other Munc13 isoforms. Mechanistically how this achieved is unknown, although one strong candidate is the calmodulin/Munc13 interaction (Junge et al., 2004) because calmodulin is a critical molecule in calciumdependent recovery (Sakaba and Neher, 2001b; Hosoi et al., 2007). Structural analyses have identified calmodulin interaction domains in all Munc13 isoforms, but their affinities in the context of the full-length molecule are unknown (RodríguezCastañeda et al., 2010a,b). Work from chromaffin cells has demonstrated that ubMunc13-2 has a higher affinity for calmodulin than other Munc13 isoforms in a calcium-dependent manner and, contrary to our finding in the calyx, would predict that loss of Munc13-2 should result in a slowing down of calciumdependent recovery (Zikich et al., 2008). We propose that the abundance and localization of Munc13-1, at the calyx, may explain this discrepancy.

\section{Munc13 and neuronal circuits}

The calyx of Held/MNTB synapse located within the auditory brainstem circuit is involved in the sensory processing of sound intensity and localization, a task that requires a high degree of synaptic reliability (Grothe et al., 2010; Borst and Soria van Hoeve, 2012). Based on our finding that Munc13-1 is the dominant isoform in the calyx, it is reasonable to assume that Munc13-1 is the ideal Munc13 isoform in other synapses in which synaptic reliability is crucial, such as thalamocortical inputs to layer 4, or retinogeniculate afferents (Lee and Sherman, 2011). Because Munc13-1 is the only isoform highly localized to the AZ (Fig. 3), it ensures that fusion-competent synaptic vesicles will have a higher probability of being tightly coupled to calcium channels and more likely to be released on AP firing, thereby promoting reliable synchronous transmitter release in the network. Together, our data indicate that the regulation of Munc13 isoform expression within a synapse may represent a novel strategic solution to maintain synaptic reliability in response to highfrequency firing.

\section{References}

Andrews-Zwilling YS, Kawabe H, Reim K, Varoqueaux F, Brose N (2006) Binding to Rab3A-interacting molecule RIM regulates the presynaptic recruitment of Munc13-1 and ubMunc13-2. J Biol Chem 281:1972019731. CrossRef Medline

Augustin I, Rosenmund C, Südhof TC, Brose N (1999a) Munc13-1 is essential for fusion competence of glutamatergic synaptic vesicles. Nature 400 : 457-461. CrossRef Medline
Augustin I, Betz A, Herrmann C, Jo T, Brose N (1999b) Differential expression of two novel Munc13 proteins in rat brain. Biochem J 337:363-371. Medline

Augustin I, Korte S, Rickmann M, Kretzschmar HA, Sudhof TC, Herms JW, Brose N (2001) The cerebellum-specific Munc13 isoform Munc13-3 regulates cerebellar synaptic transmission and motor learning in mice. J Neurosc 21:10-17. Medline

Bao J, Reim K, Sakaba T (2010) Target-dependent feedforward inhibition mediated by short-term synaptic plasticity in the cerebellum. J Neurosci 30:8171-8179. CrossRef Medline

Betz A, Okamoto M, Benseler F, Brose N (1997) Direct interaction of the rat unc-13 homologue Munc13-1 with the $\mathrm{N}$ terminus of syntaxin. J Biol Chem 272:2520-2526. CrossRef Medline

Betz A, Thakur P, Junge HJ, Ashery U, Rhee JS, Scheuss V, Rosenmund C, Rettig J, Brose N (2001) Functional interaction of the active zone proteins Munc13-1 and RIM1 in synaptic vesicle priming. Neuron 30:183196. CrossRef Medline

Borst JG, Soria van Hoeve J (2012) The calyx of Held synapse: from model synapse to auditory relay. Annu Rev Physiol 74:199-224. CrossRef Medline

Breustedt J, Gundlfinger A, Varoqueaux F, Reim K, Brose N, Schmitz D (2010) Munc13-2 differentially affects hippocampal synaptic transmission and plasticity. Cereb Cortex 20:1109-1120. CrossRef Medline

Brose N, Hofmann K, Hata Y, Südhof TC (1995) Mammalian homologues of Caenorhabditis elegans unc-13 gene define novel family of C2-domain proteins. J Biol Chem 270:25273-25280. CrossRef Medline

Cooper B, Hemmerlein M, Ammermüller J, Imig C, Reim K, Lipstein N, Kalla S, Kawabe H, Brose N, Brandstätter JH, Varoqueaux F (2012) Munc13independent vesicle priming at mouse photoreceptor ribbon synapses. J Neurosci 32:8040-8052. CrossRef Medline

Dulubova I, Lou X, Lu J, Huryeva I, Alam A, Schneggenburger R, Südhof TC, Rizo J (2005) A Munc13/RIM/Rab3 tripartite complex: from priming to plasticity? EMBO J 24:2839-2850. CrossRef Medline

Fedchyshyn MJ, Wang LY (2005) Developmental transformation of the release modality at the calyx of held synapse. J Neurosci 25:4131-4140. CrossRef Medline

Forsythe ID, Barnes-Davies M (1993a) The binaural auditory pathway: membrane currents limiting multiple action potential generation in the rat medial nucleus of the trapezoid body. Proceed Biol Sci 251:143-150. CrossRef Medline

Forsythe ID, Barnes-Davies M (1993b) The binaural auditory pathway: excitatory amino acid receptors mediate dual timecourse excitatory postsynaptic currents in the rat medial nucleus of the trapezoid body. Proceed Biol Sci 251:151-157. CrossRef Medline

Grothe B, Pecka M, McAlpine D (2010) Mechanisms of sound localization in mammals. Physiol Rev 90:983-1012. CrossRef Medline

Guan R, Dai H, Rizo J (2008) Binding of the Munc13-1 MUN domain to membrane-anchored SNARE complexes. Biochemistry 47:1474-1481. CrossRef Medline

Hosoi N, Sakaba T, Neher E (2007) Quantitative analysis of calciumdependent vesicle recruitment and its functional role at the calyx of Held synapse. J Neurosci 27:14286-14298. CrossRef Medline

Junge HJ, Rhee JS, Jahn O, Varoqueaux F, Spiess J, Waxham MN, Rosenmund C, Brose N (2004) Calmodulin and Munc13 form a Ca ${ }^{2+}$ sensor/effector complex that controls short-term synaptic plasticity. Cell 118:389401. CrossRef Medline

Kalla S, Stern M, Basu J, Varoqueaux F, Reim K, Rosenmund C, Ziv NE, Brose N (2006) Molecular dynamics of a presynaptic active zone protein studied in Munc13-1-enhanced yellow fluorescent protein knock-in mutant mice. J Neurosci 26:13054-13066. CrossRef Medline

Kandler K, Friauf E (1993) Pre- and postnatal development of efferent connections of the cochlear nucleus in the rat. J Comp Neurol 328:161-184. CrossRef Medline

Klemmer P, Smit AB, Li KW (2009) Proteomics analysis of immunoprecipitated synaptic protein complexes. J Proteomics 72:82-90. CrossRef Medline

Koch H, Hofmann K, Brose N (2000) Definition of Munc13-homologydomains and characterization of a novel ubiquitously expressed Munc13 isoform. Biochem J 349:247-253. CrossRef Medline

Lee CC, Sherman SM (2011) On the classification of pathways in the auditory midbrain, thalamus, and cortex. Hear Res 276:79-87. CrossRef Medline 
Lee JS, Ho WK, Lee SH (2010) Post-tetanic increase in the fast-releasing synaptic vesicle pool at the expense of the slowly releasing pool. J Gen Physiol 136:259-272. CrossRef Medline

Lee JS, Ho WK, Lee SH (2012) Actin-dependent rapid recruitment of reluctant synaptic vesicles into a fast-releasing vesicle pool. Proc Natl Acad Sci USA 109:E765-E774. CrossRef Medline

Li W, Ma C, Guan R, Xu Y, Tomchick DR, Rizo J (2011) The crystal structure of a Munc13 C-terminal module exhibits a remarkable similarity to vesicle tethering factors. Structure 19:1443-1455. CrossRef Medline

Limbach C, Laue MM, Wang X, Hu B, Thiede N, Hultqvist G, Kilimann MW (2011) Molecular in situ topology of Aczonin/Piccolo and associated proteins at the mammalian neurotransmitter release site. Proc Natl Acad Sci USA 108:E392-E401. CrossRef Medline

Montesinos MS, Chen Z, Young SM Jr (2011) pUNISHER: a high-level expression cassette for use with recombinant viral vectors for rapid and long term in vivo neuronal expression in the CNS. J Neurophysiol 106:32303244. CrossRef Medline

Müller CS, Haupt A, Bildl W, Schindler J, Knaus HG, Meissner M, Rammner B, Striessnig J, Flockerzi V, Fakler B, Schulte U (2010) Quantitative proteomics of the Cav2 channel nano-environments in the mammalian brain. Proc Natl Acad Sci USA 107:14950-14957. CrossRef Medline

Neher E, Sakaba T (2001a) Combining deconvolution and noise analysis for the estimation of transmitter release rates at the calyx of Held. J Neurosci 21:444-461. Medline

Neher E, Sakaba T (2001b) Estimating transmitter release rates from postsynaptic current fluctuations. J Neurosci 21:9638-9654. Medline

Neher E, Sakaba T (2008) Multiple roles of calcium ions in the regulation of neurotransmitter release. Neuron 59:861-872. CrossRef Medline

Pan B, Zucker RS (2009) A general model of synaptic transmission and short-term plasticity. Neuron 62:539-554. CrossRef Medline

Pilpel N, Landeck N, Klugmann M, Seeburg PH, Schwarz MK (2009) Rapid, reproducible transduction of select forebrain regions by targeted recombinant virus injection into the neonatal mouse brain. J Neurosci Methods 182:55-63. CrossRef Medline

Rodríguez-Castañeda F, Coudevylle N, Becker S, Brose N, Carlomagno T, Griesinger C (2010a) $1 \mathrm{H}, 13 \mathrm{C}$ and $15 \mathrm{~N}$ resonance assignments of the Calmodulin-Munc13-1 peptide complex. Biomol NMR Assign 4:45-48. CrossRef Medline

Rodríguez-Castañeda F, Maestre-Martínez M, Coudevylle N, Dimova K, Junge H, Lipstein N, Lee D, Becker S, Brose N, Jahn O, Carlomagno T, Griesinger C (2010b) Modular architecture of Munc13/calmodulin complexes: dual regulation by $\mathrm{Ca}^{2+}$ and possible function in short-term synaptic plasticity. EMBO J 29:680-691. CrossRef Medline

Rosenmund C, Sigler A, Augustin I, Reim K, Brose N, Rhee JS (2002) Differential control of vesicle priming and short-term plasticity by Munc13 isoforms. Neuron 33:411-424. CrossRef Medline

Sakaba T (2006) Roles of the fast-releasing and the slowly releasing vesicles in synaptic transmission at the calyx of held. J Neurosci 26:5863-5871. CrossRef Medline

Sakaba T, Neher E (2001a) Quantitative relationship between transmitter release and calcium current at the calyx of held synapse. J Neurosci 21: 462-476. Medline
Sakaba T, Neher E (2001b) Calmodulin mediates rapid recruitment of fastreleasing synaptic vesicles at a calyx-type synapse. Neuron 32:1119-1131. CrossRef Medline

Sakaba T, Neher E (2003) Direct modulation of synaptic vesicle priming by GABA(B) receptor activation at a glutamatergic synapse. Nature 424:775778. CrossRef Medline

Sakaba T, Stein A, Jahn R, Neher E (2005) Distinct kinetic changes in neurotransmitter release after SNARE protein cleavage. Science 309:491-494. CrossRef Medline

Schneggenburger R, Meyer AC, Neher E (1999) Released fraction and total size of a pool of immediately available transmitter quanta at a calyx synapse. Neuron 23:399-409. CrossRef Medline

Südhof TC (2012) The presynaptic active zone. Neuron 75:11-25. CrossRef Medline

Taschenberger H, von Gersdorff H (2000) Fine-tuning an auditory synapse for speed and fidelity: developmental changes in presynaptic waveform, EPSC kinetics, and synaptic plasticity. J Neurosci 20:9162-9173. Medline

Taschenberger H, Leão RM, Rowland KC, Spirou GA, von Gersdorff H (2002) Optimizing synaptic architecture and efficiency for highfrequency transmission. Neuron 36:1127-1143. CrossRef Medline

Varoqueaux F, Sigler A, Rhee JS, Brose N, Enk C, Reim K, Rosenmund C (2002) Total arrest of spontaneous and evoked synaptic transmission but normal synaptogenesis in the absence of Munc13-mediated vesicle priming. Proc Natl Acad Sci USA 99:9037-9042. CrossRef Medline

Varoqueaux F, Sons MS, Plomp JJ, Brose N (2005) Aberrant morphology and residual transmitter release at the Munc13-deficient mouse neuromuscular synapse. Mol Cell Biol 25:5973-5984. CrossRef Medline

Wang LY, Kaczmarek LK (1998) High-frequency firing helps replenish the readily releasable pool of synaptic vesicles. Nature 394:384-388. CrossRef Medline

Wang LY, Neher E, Taschenberger H (2008) Synaptic vesicles in mature calyx of Held synapses sense higher nanodomain calcium concentrations during action potential-evoked glutamate release. J Neurosci 28:14450-14458. CrossRef Medline

Wang X, Hu B, Zieba A, Neumann NG, Kasper-Sonnenberg M, Honsbein A Hultqvist G, Conze T, Witt W, Limbach C, Geitmann M, Danielson H, Kolarow R, Niemann G, Lessmann V, Kilimann MW (2009) A protein interaction node at the neurotransmitter release site: domains of Aczonin/Piccolo, Bassoon, CAST, and rim converge on the N-terminal domain of Munc13-1. J Neurosci 29:12584-12596. CrossRef Medline

Yang YM, Fedchyshyn MJ, Grande G, Aitoubah J, Tsang CW, Xie H, Ackerley CA, Trimble WS, Wang LY (2010) Septins regulate developmental switching from microdomain to nanodomain coupling of $\mathrm{Ca}^{2+}$ influx to neurotransmitter release at a central synapse. Neuron 67:100-115. CrossRef Medline

Young SM Jr, Neher E (2009) Synaptotagmin has an essential function in synaptic vesicle positioning for synchronous release in addition to its role as a calcium sensor. Neuron 63:482-496. CrossRef Medline

Zikich D, Mezer A, Varoqueaux F, Sheinin A, Junge HJ, Nachliel E, Melamed R, Brose N, Gutman M, Ashery U (2008) Vesicle priming and recruitment by ubMunc13-2 are differentially regulated by calcium and calmodulin. J Neurosci 28:1949-1960. CrossRef Medline 